Supporting Information for

\title{
A Photocaged Cell-Permeable Ubiquitin Probe for Temporal Profiling of Deubiquitinating Enzymes
}

\author{
Weijun Gui, Siqi Shen, Zhihao Zhuang* \\ Department of Chemistry and Biochemistry, University of Delaware, 214A Drake Hall, \\ Newark, Delaware, 19716, USA
}

\section{Table of Contents}

\section{Supplemental Figures and Tables}

Figure S1. ESI-MS characterization of time dependent 365 nm UV irradiation of HA-Cys-Ub-TZ------S3

Figure S2. ESI-MS characterization of USP2-CD incubated with HA-Cys-Ub-TZ without UV irradiation-

Figure S3. Nano-flow LC-MS/MS analysis of the labeled USP2-CD by HA-Cys-Ub-TZ probe after trypsin digestion-----------------------------------------------------------------------------------------------------S5

Figure S4. Structure of ubiquitin-based probes--------------------------------------------------------S6

Figure S5. Wild type USP2-CD and USP2-CD mutants labeling by HA-Cys-Ub-TZ -------------------S7

Figure S6. UCHL3 labeling by $15 \mu \mathrm{M}$ tetrazole probes---------------------------------------------------S8

Figure S7. UCHL1 labeling by $15 \mu \mathrm{M}$ tetrazole probes ----------------------------------------------------S9

Figure S8. BSA labeling by $15 \mu \mathrm{M}$ tetrazole probes ----------------------------------------------- S10

Figure S9. ESI-MS characterization of HA-Cys-Ub-TZ probe incubated with glutathione upon $365 \mathrm{~nm}$

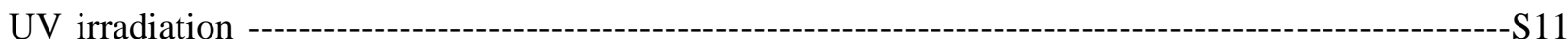

Figure S10. ESI-MS characterization of HA-Cys-Ub-TZ probe incubated with DTT upon $365 \mathrm{~nm}$ UV irradiation $-\mathrm{S} 12$

Figure S11. Wild type USP2-CD labeling by $15 \mu \mathrm{M}$ HA-Cys-Ub-TZ in the presence of different concentrations of DTT$-\mathrm{S} 13$

Figure S12. USP2-CD and UCHL3 labeling by different concentrations of HA-Cys-Ub-TZ-----------S14

Figure S13: Heat map representing the LFQ intensity scores of significantly enriched protein groups other than DUBs by $15 \mu \mathrm{M}$ HA-Cys(cR 10$)-U b-T Z$ upon $365 \mathrm{~nm}$ UV irradiation$-\mathrm{S} 15$

Figure S14: Volcano plot of protein groups pulled down in the absence of UV irradiation with $15 \mu \mathrm{M}$ HA-Cys $\left(\mathrm{cR}_{10}\right)$-Ub-TZ treatment versus control pulldown without probe $-\mathrm{S} 16$

Figure S15: Expression levels of cyclin A and GAPDH in synchronized HeLa cells $-\mathrm{S} 17$

Figure S16: Volcano plot of pairwise comparison of protein groups pulled down in $\mathrm{G} 1 / \mathrm{S}$ phase by $15 \mu \mathrm{M}$ HA-Cys $\left(\mathrm{cR}_{10}\right)-\mathrm{Ub}-\mathrm{TZ}$ with $365 \mathrm{~nm} \mathrm{UV}$ irradiation relative to no UV irradiation $-\mathrm{S} 18$ 
Figure S17: Heat map representing the LFQ intensity scores of G1/S phase DUBs significantly enriched by $15 \mu$ M HA-Cys $\left(\mathrm{cR}_{10}\right)$-Ub-TZ upon $365 \mathrm{~nm}$ UV irradiation $-\mathrm{S} 19$

Figure S18: Volcano plot of pairwise comparison of protein groups pulled down in G2/M phase by HACys $\left(\mathrm{cR}_{10}\right)-\mathrm{Ub}-\mathrm{TZ}$ with $365 \mathrm{~nm} \mathrm{UV}$ irradiation relative to no UV irradiation $-\mathrm{S} 20$

Figure S19: Heat map representing the LFQ intensity scores of G2/M phase DUBs significantly enriched by $15 \mu \mathrm{M}$ HA-Cys $\left(\mathrm{cR}_{10}\right)$-Ub-TZ upon $365 \mathrm{~nm}$ UV irradiation $-\mathrm{S} 21$

Figure S20: Intracellular proteome-wide DUB profiling by $15 \mu \mathrm{M}$ HA-Cys $\left(\mathrm{cR}_{10}\right)-\mathrm{Ub}-\mathrm{TZ}$ with $365 \mathrm{~nm}$ UV irradiation comparing DUBs captured in different phases of cell cycle of HeLa cells and unsynchronized cells S22

Table S1. LFQ intensity scores for DUBs captured in HeLa cell using $15 \mu \mathrm{M}$ HA-Cys(cR $\left.{ }_{10}\right)-U b-T Z$-S23

Table S2. LFQ intensity scores for proteins other than DUBs significantly enriched in HeLa cell using 15 $\mu \mathrm{M}$ HA-Cys $\left(\mathrm{cR}_{10}\right)-\mathrm{Ub}-\mathrm{TZ}$

Table S3. Pairwise comparison of fold difference and $P$-value $\left(-\log _{10}\right)$ for DUBs captured in HeLa cells at different time points following the release from G1/S phase using $15 \mu \mathrm{M}$ HA-Cys(cR $\left.{ }_{10}\right)$-Ub-TZ. ---S25 Supplemental Methods S26-S28

General Information $-\mathrm{S} 29$

Experimental Procedures and Characterization Data S30

Scheme S1. Synthesis of (2-(1-methyl-1H-pyrrol-2-yl)-2H-tetrazol-5-yl)methanamine (5)--------S30-S31

Scheme S2. Generation of HA-Cys $\left(\mathrm{cR}_{10}\right)-\mathrm{Ub}-\mathrm{TZ}$ $-S 32-S 33$

References S34

${ }^{1} \mathrm{H}$ and ${ }^{13} \mathrm{C}$ NMR Spectra $-S 35-S 38$ 
A

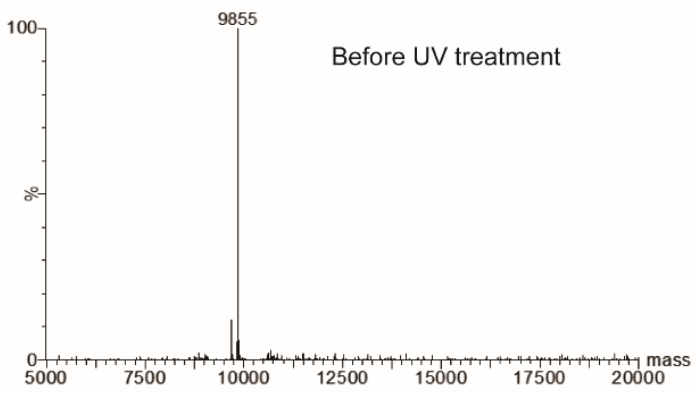

C

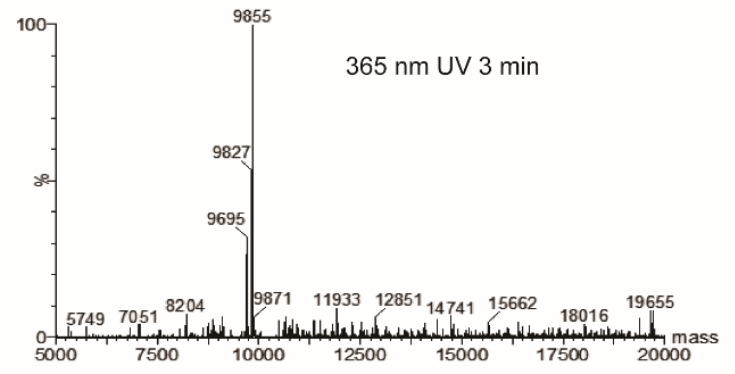

E

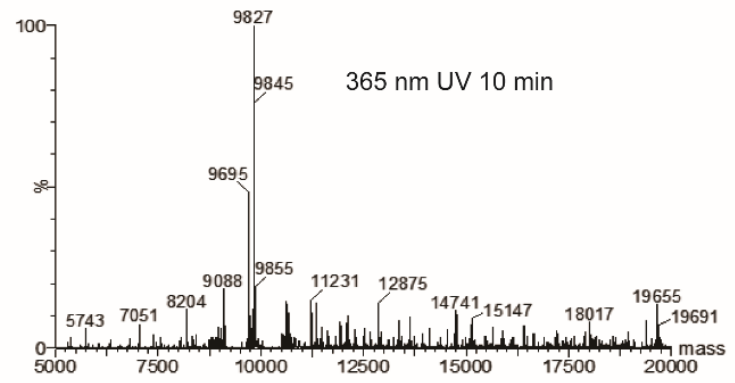

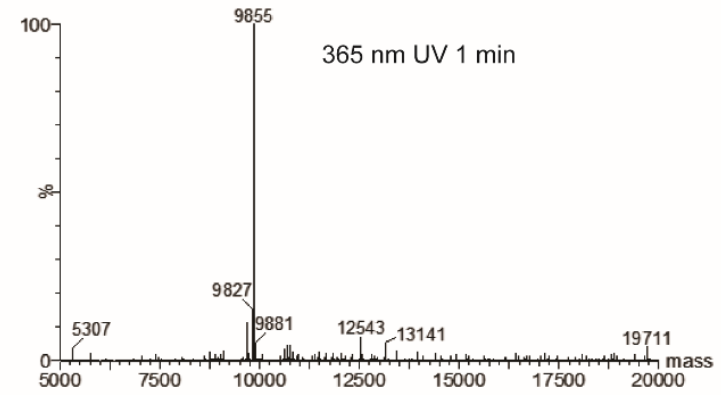

D

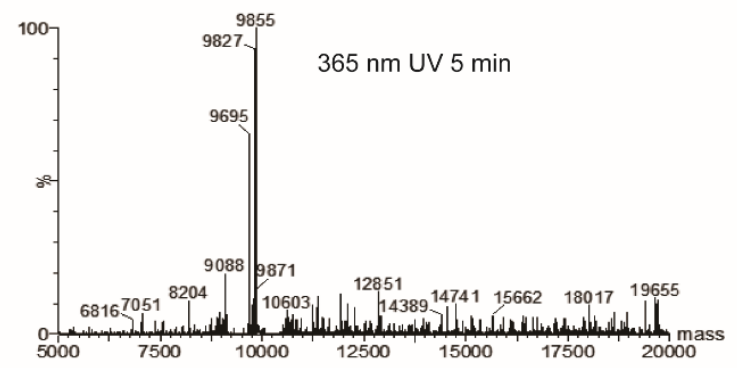

F

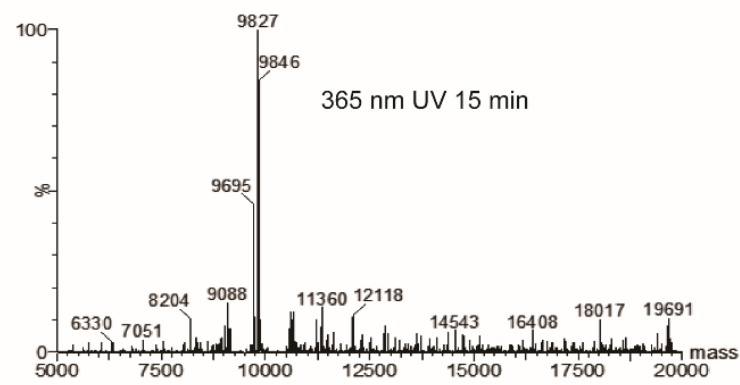

G

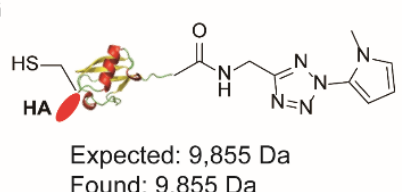

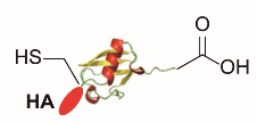

Expected: 9,695 Da Found: $9,695 \mathrm{Da}$<smiles>Cn1cccc1CCC(=O)NCC#N</smiles>

Expected: 9,827 Da Found: 9,827 Da

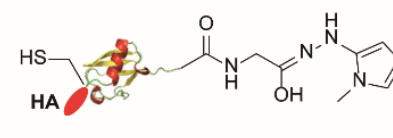

Expected: $9,845 \mathrm{Da}$ Found: 9,$845 ; 9,846 \mathrm{Da}$

Figure S1. ESI-MS characterization of time dependent $365 \mathrm{~nm}$ UV irradiation of HA-Cys-Ub-TZ. A) ESIMS characterization of $15 \mu \mathrm{M}$ HA-Cys-Ub-TZ before UV irradiation; B-F) ESI-MS characterization of 15 $\mu \mathrm{M}$ HA-Cys-Ub-TZ UV irradiated at $365 \mathrm{~nm}$ for 1, 3, 5, 10, 15 mins, respectively; G) Assignment of the major peaks found in the ESI-MS spectrometry. 

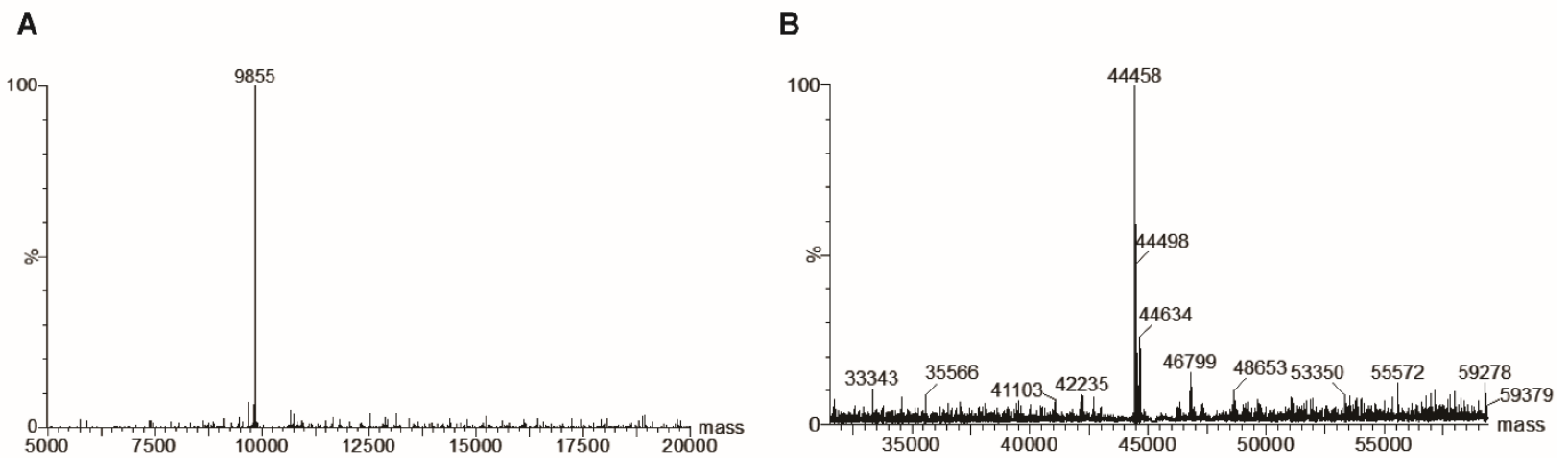

Figure S2. ESI-MS characterization of HA-Cys-Ub-TZ and HA-Cys-Ub-TZ incubated with USP2-CD without UV irradiation. A) ESI-MS characterization of HA-Cys-Ub-TZ; B) ESI-MS characterization of USP2-CD incubated with HA-Cys-Ub-TZ without UV irradiation. 


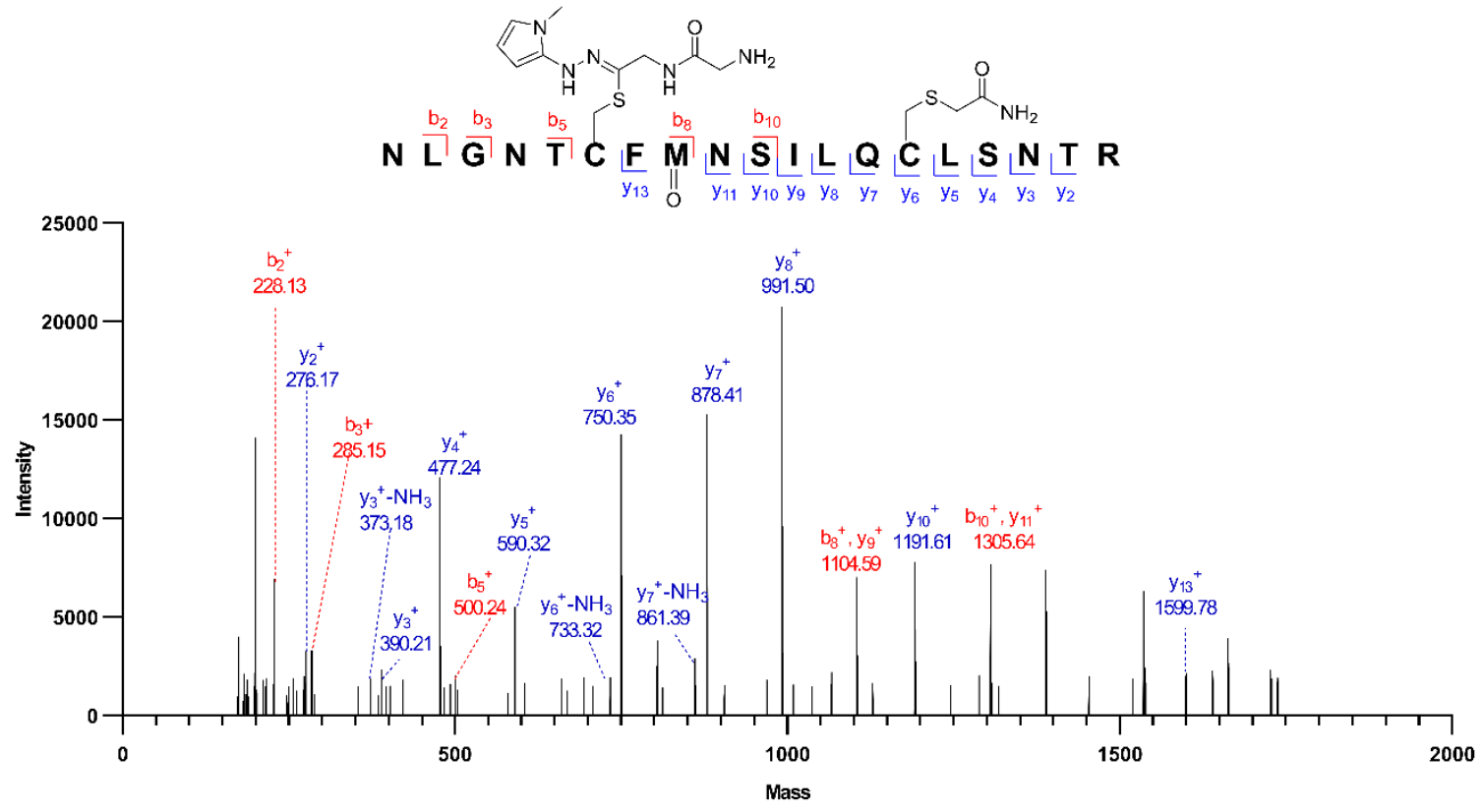

Figure S3. Nano-flow LC-MS/MS analysis of the labeled USP2-CD by HA-Cys-Ub-TZ probe after trypsin digestion. High-energy collision dissociation MS2 spectrum showing the identification of active site cysteine on USP2-CD modification by tetrazole probe peptide fragment. 
A

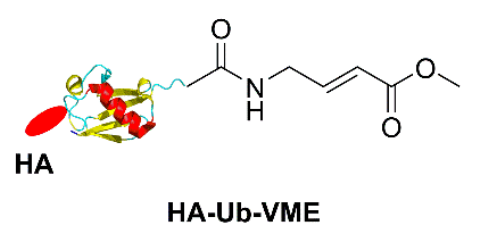

C

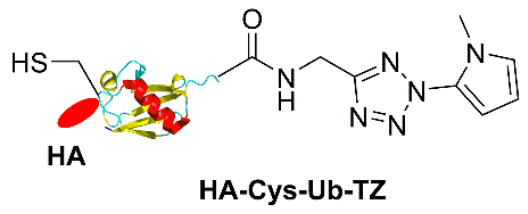

B

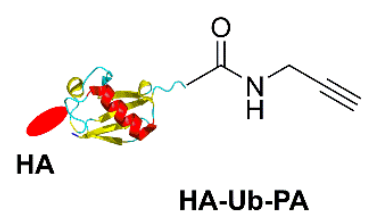

D

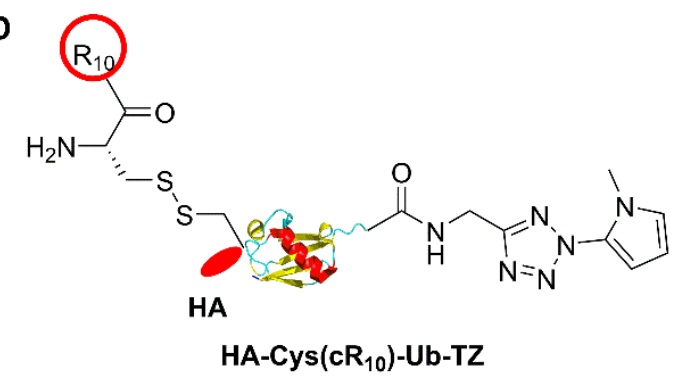

Figure S4. Structure of ubiquitin-based probes. A) Structure of probe HA-Ub-VME; B) Structure of probe HA-Ub-PA; C) Structure of probe HA-Cys-Ub-TZ; D) Structure of probe HA-Cys(cR 10$)-\mathrm{Ub}-\mathrm{TZ}$. 


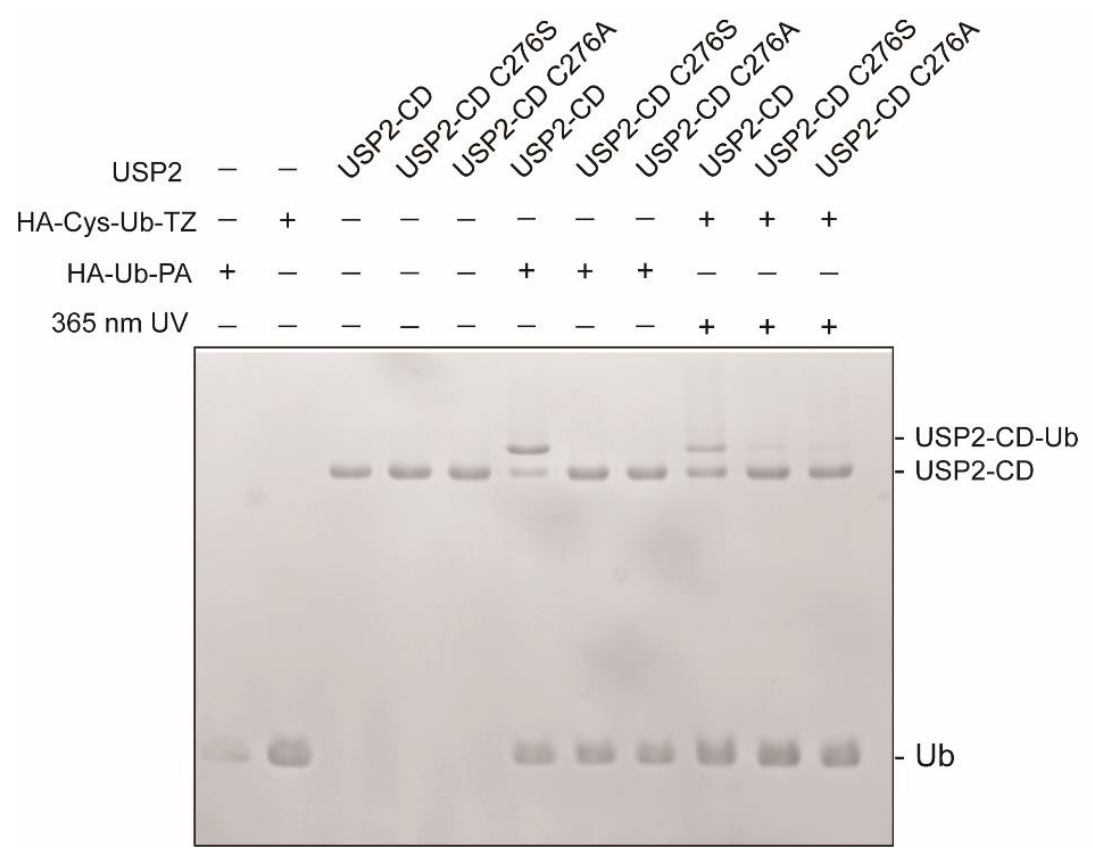

Figure S5. Wild-type USP2-CD and USP2-CD mutants labeling by $15 \mu \mathrm{M}$ HA-Cys-Ub-TZ, analyzed using $20 \%$ SDS-PAGE gel and stained with Coomassie brilliant blue. HA-Ub-PA probe was used for a comparison. 


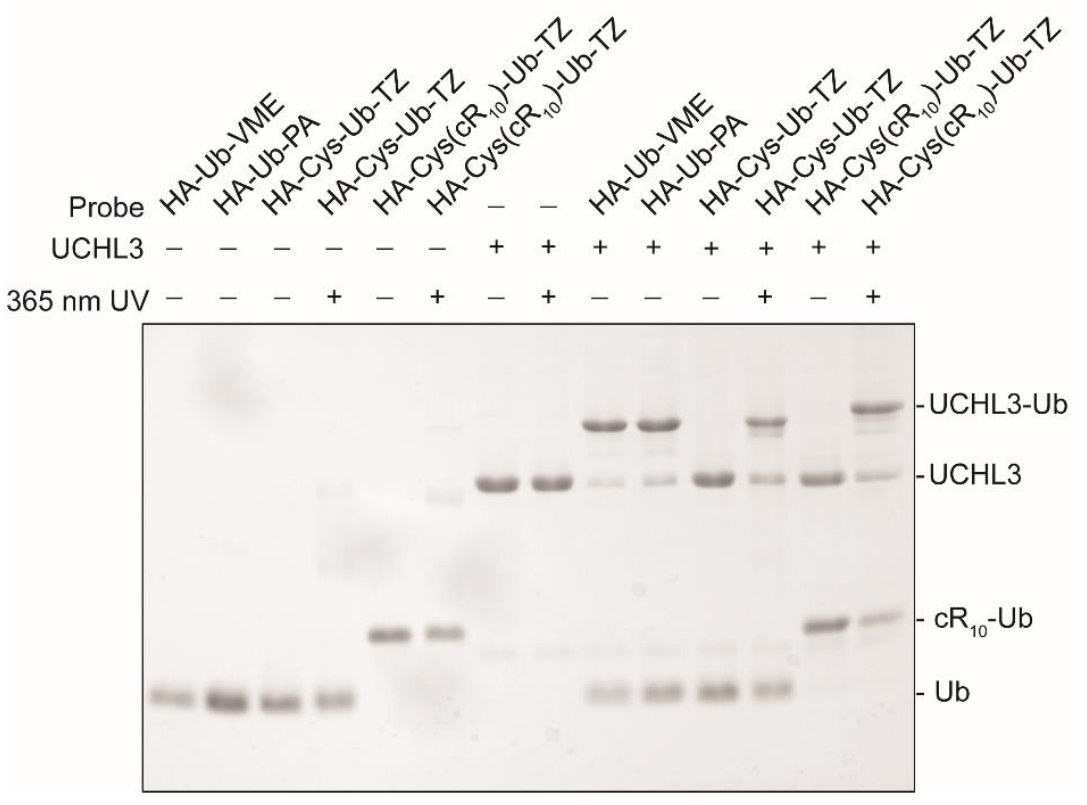

Figure S6. UCHL3 labeling by $15 \mu \mathrm{M}$ Ub-TZ probes, analyzed using 20\% SDS-PAGE gel and stained with Coomassie brilliant blue. HA-Ub-VME and HA-Ub-PA were used as a comparison. 


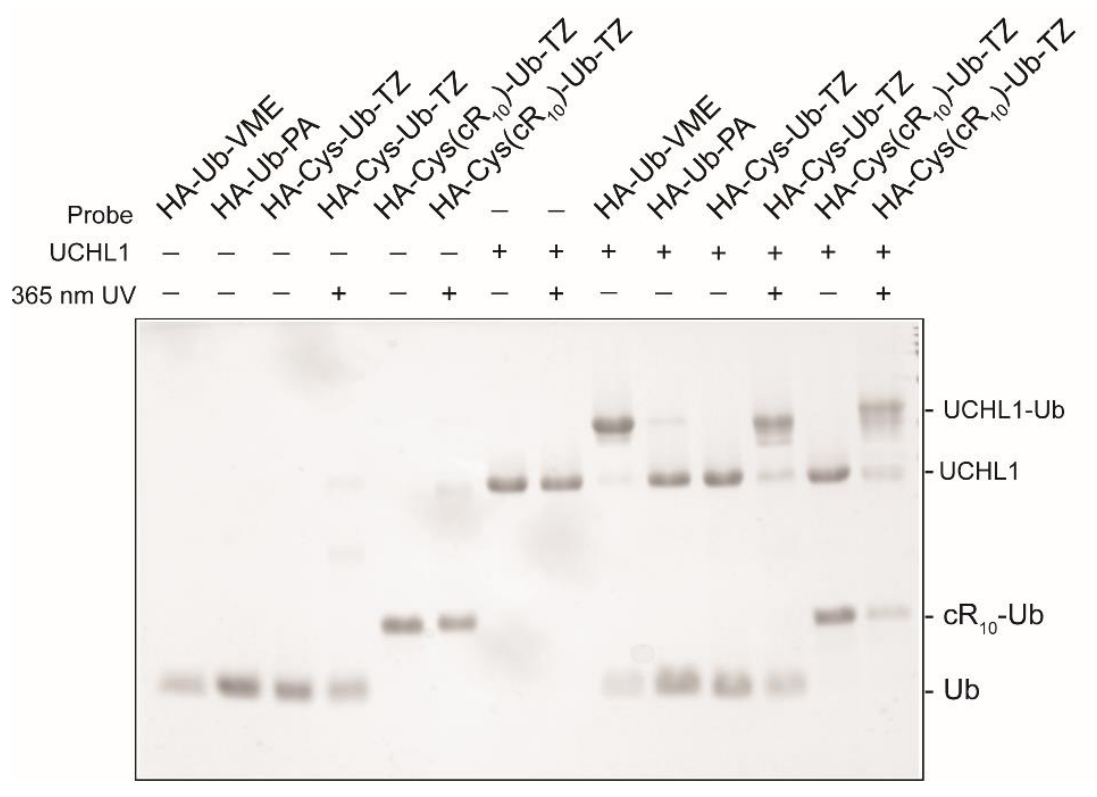

Figure S7. UCHL1 labeling by $15 \mu \mathrm{M}$ Ub-TZ probes, analyzed using $20 \%$ SDS-PAGE gel and stained with Coomassie brilliant blue. HA-Ub-VME and HA-Ub-PA were used as a comparison. 


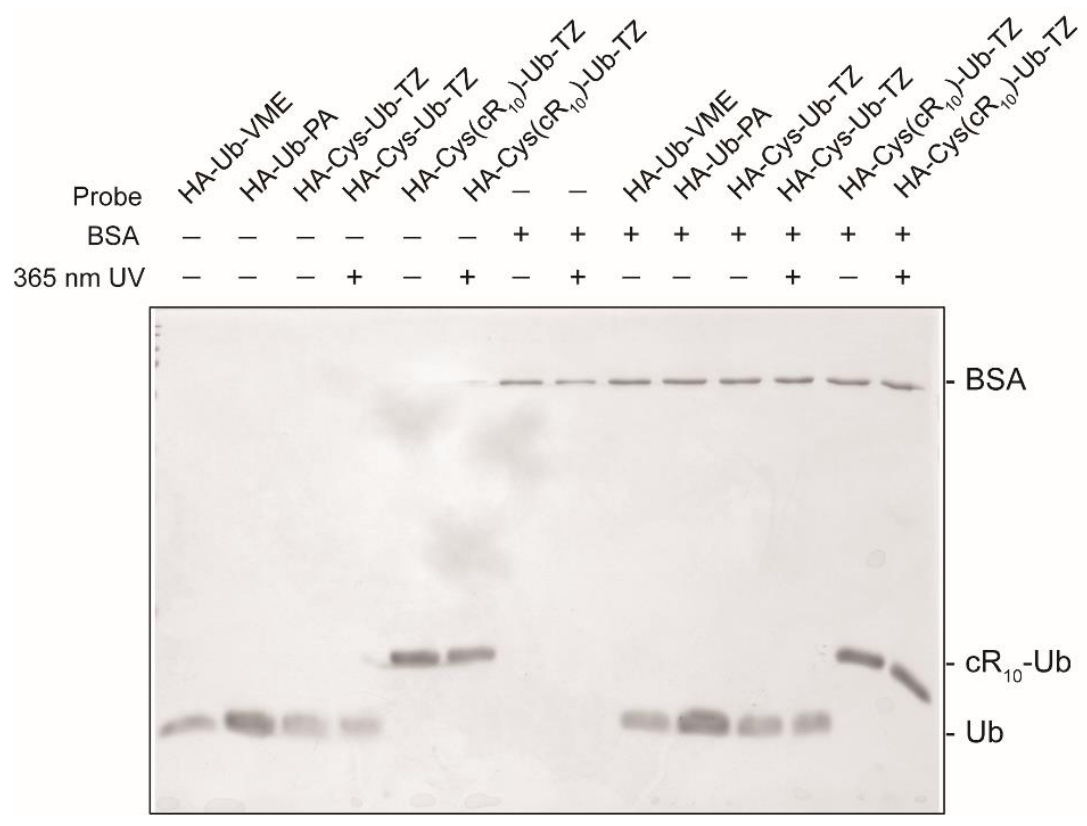

Figure S8. BSA labeling by $15 \mu \mathrm{M}$ Ub-TZ probes, analyzed using $20 \%$ SDS-PAGE gel and stained with Coomassie brilliant blue. HA-Ub-PA and HA-Ub-VME were used as comparison. 
A

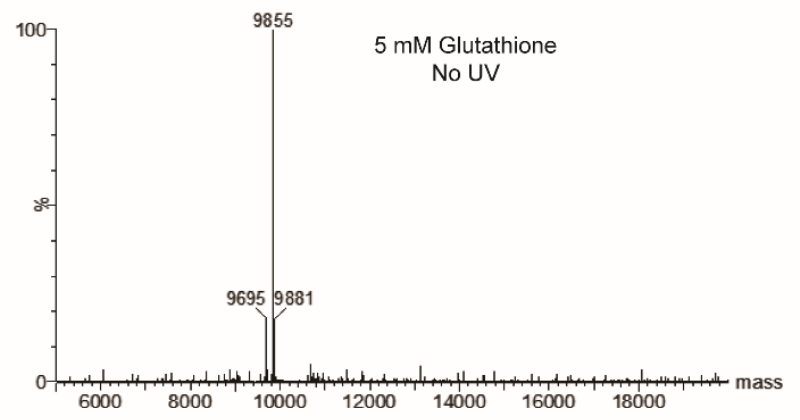

C

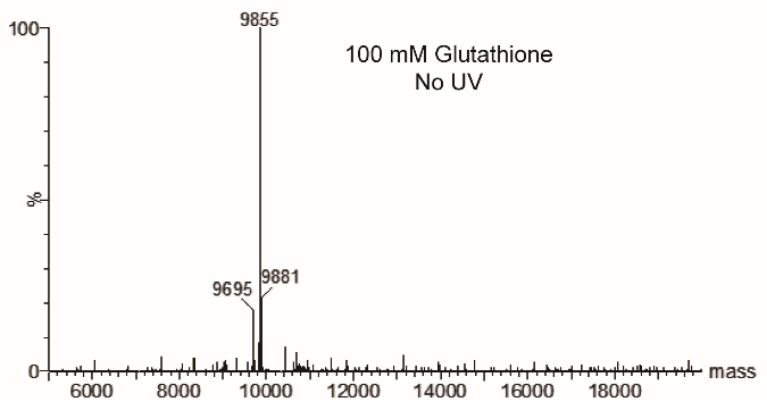

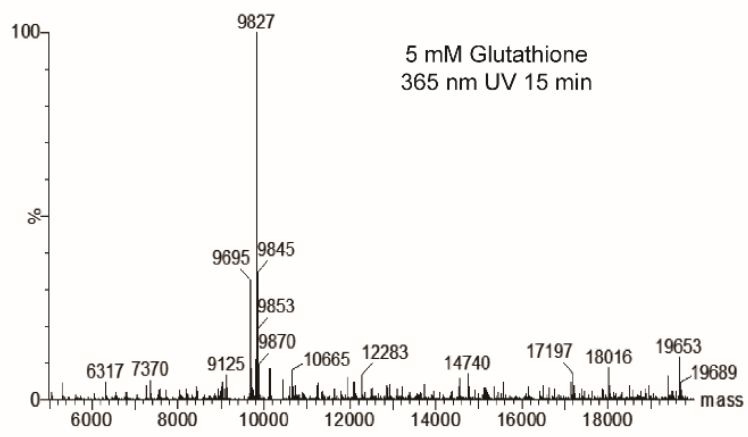

D

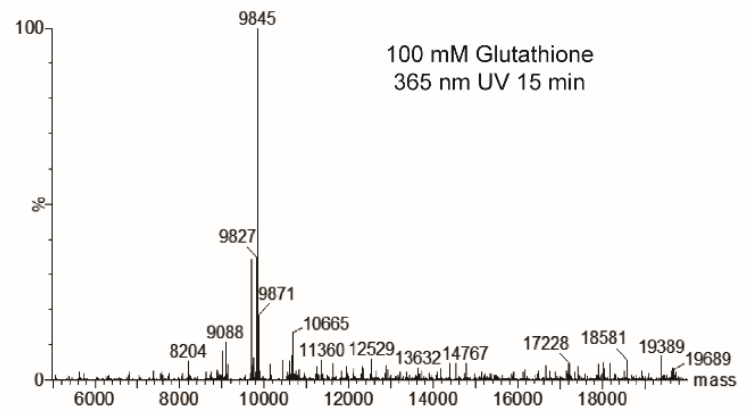

Figure S9. ESI-MS characterization of HA-Cys-Ub-TZ probe incubated with glutathione upon $365 \mathrm{~nm}$ UV irradiation. A) ESI-MS characterization of $15 \mu \mathrm{M}$ HA-Cys-Ub-TZ incubated with $5 \mathrm{mM}$ glutathione without UV irradiation; B) ESI-MS characterization of $15 \mu \mathrm{M}$ HA-Cys-Ub-TZ incubated with $5 \mathrm{mM}$ glutathione with $365 \mathrm{~nm}$ UV irradiation for $15 \mathrm{~min}$; C) ESI-MS characterization of $15 \mu \mathrm{M}$ HA-Cys-Ub-TZ incubated with $100 \mathrm{mM}$ glutathione without UV irradiation; D) ESI-MS characterization of $15 \mu \mathrm{M} \mathrm{HA}$ Cys-Ub-TZ incubated with $100 \mathrm{mM}$ glutathione with $365 \mathrm{~nm}$ UV irradiation for $15 \mathrm{~min}$. 9,827 Da corresponds to the nitrilimine intermediate HA-Cys-Ub-NM and 9,845 Da corresponds to the hydroxylation product of nitrilimine (HA-Cys-Ub-NM-OH). 
A

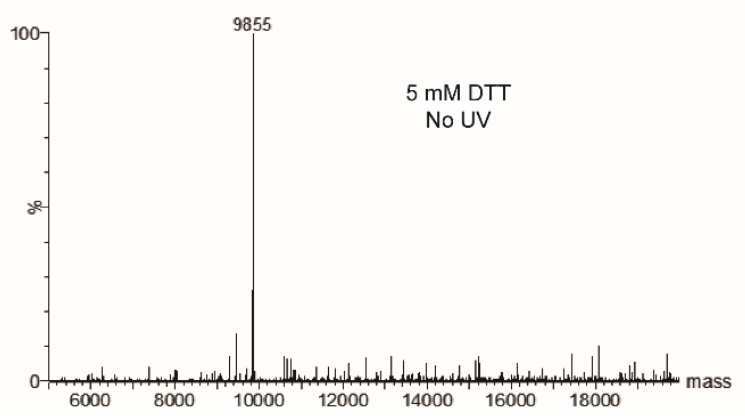

B

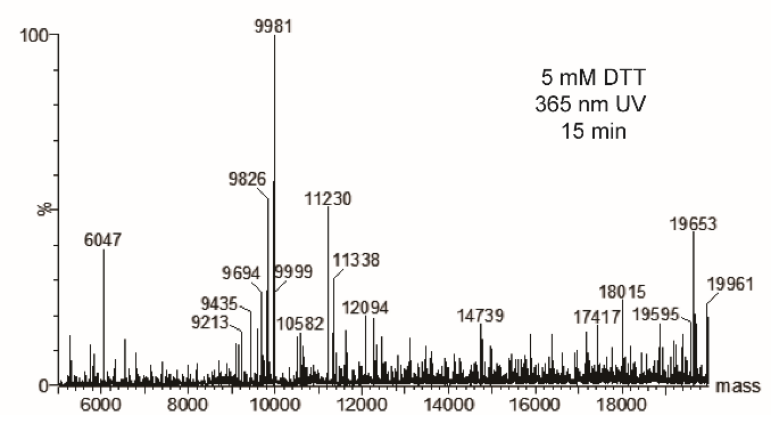

Figure S10. ESI-MS characterization of HA-Cys-Ub-TZ probe incubated with DTT upon $365 \mathrm{~nm}$ UV irradiation. A) ESI-MS characterization of $15 \mu \mathrm{M}$ HA-Cys-Ub-TZ incubated with 5 mM DTT without UV irradiation; B) ESI-MS characterization of $15 \mu \mathrm{M}$ HA-Cys-Ub-TZ incubated with $5 \mathrm{mM}$ DTT with $365 \mathrm{~nm}$ UV irradiation for 15 min. The major peak 9,981 Da agrees with the expected mass of HA-Cys-Ub-NMDTT. 


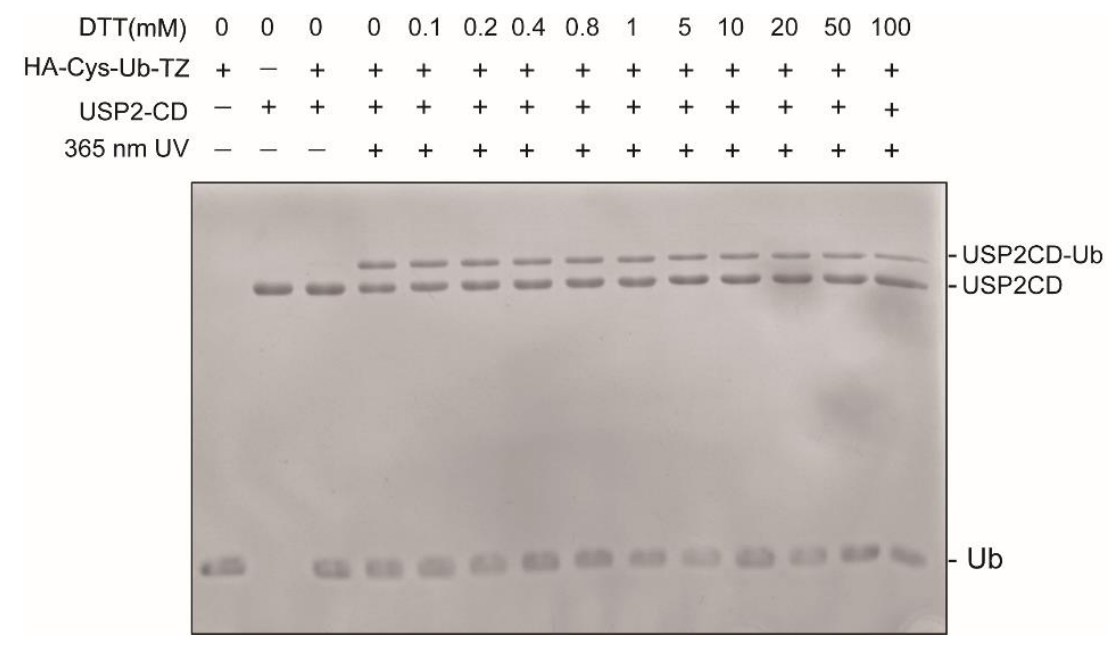

Figure S11. Wild type USP2-CD labeling by $15 \mu \mathrm{M}$ HA-Cys-Ub-TZ in the presence of different concentrations of DTT. The labeling product was analyzed using 20\% SDS-PAGE gel and stained with Coomassie brilliant blue. 


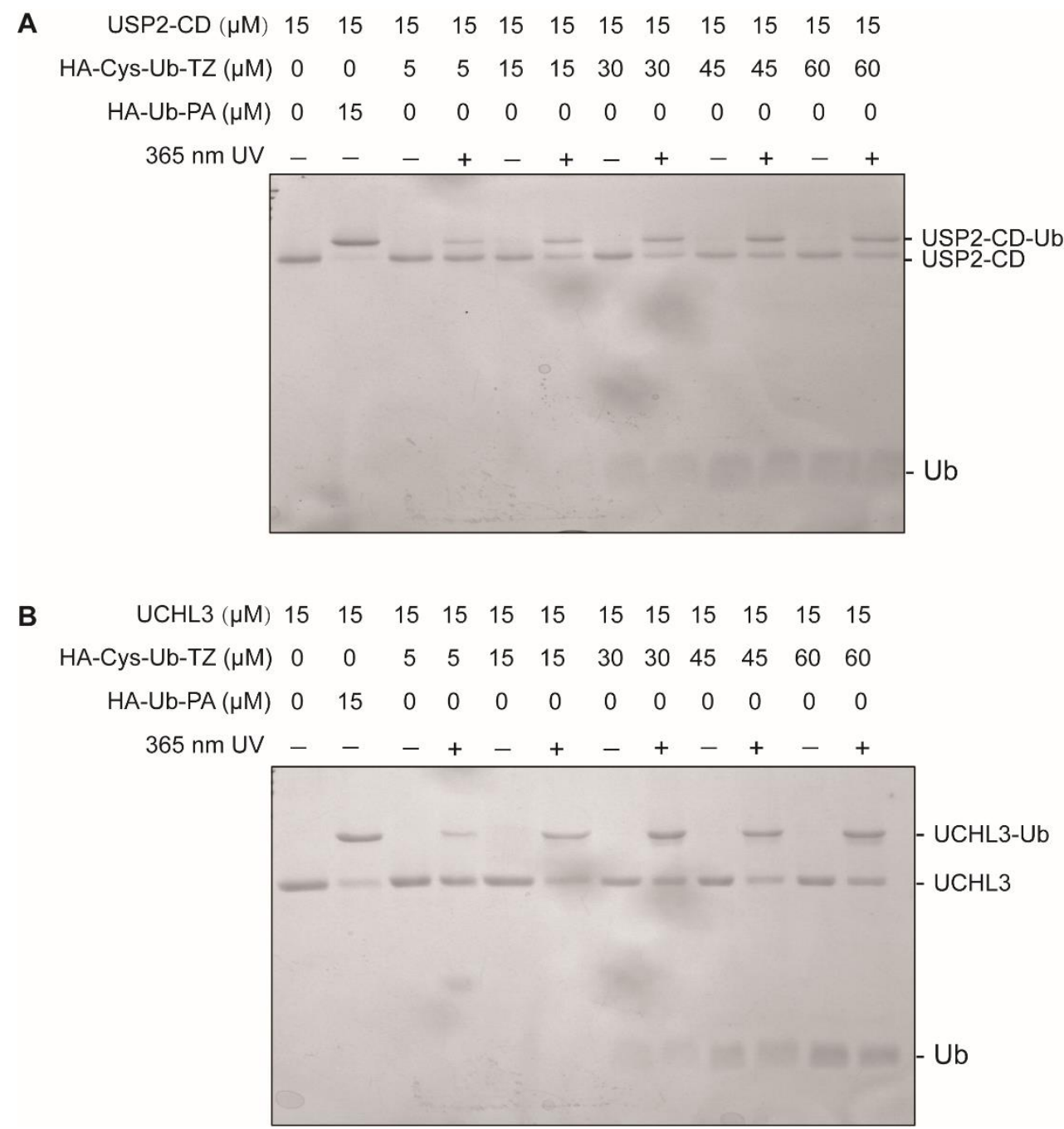

Figure S12. USP2-CD and UCHL3 labeling by different concentrations of HA-Cys-Ub-TZ. A) USP2-CD labeling by different concentration of HA-Cys-Ub-TZ; B) UCHL3 labeling by different concentration of HA-Cys-Ub-TZ. HA-Ub-PA was used as a control probe. 


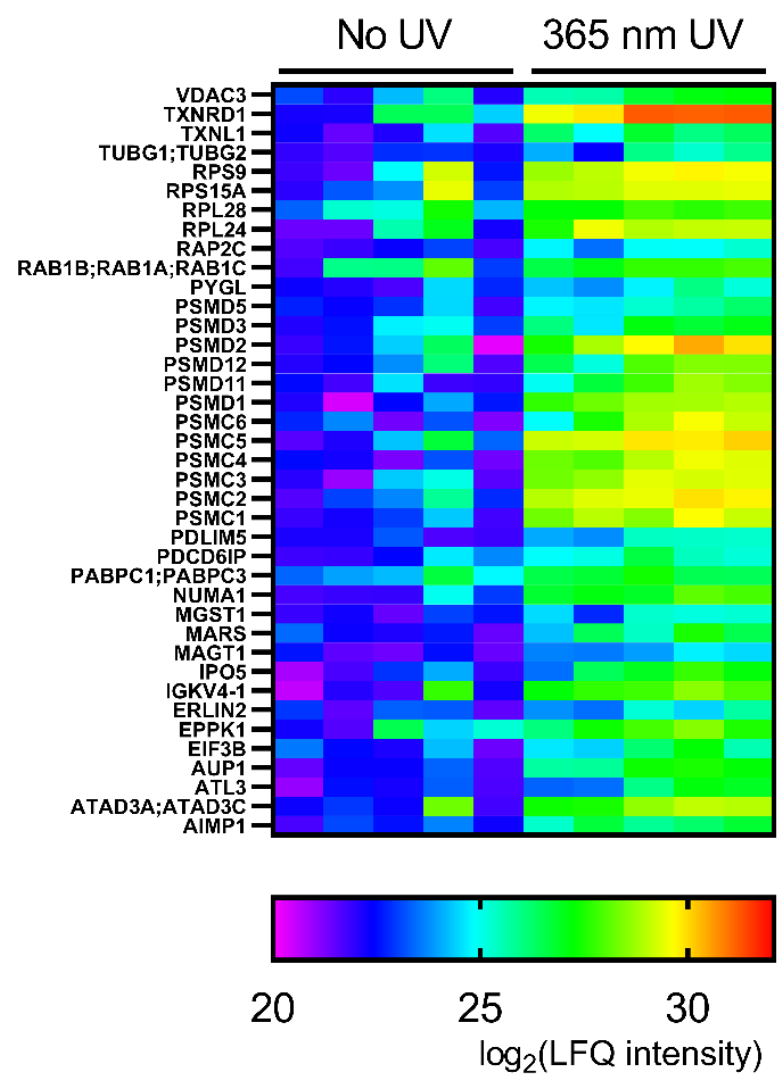

Figure S13: Heat map representing the LFQ intensity scores of significantly enriched protein groups other than DUBs by $15 \mu \mathrm{M}$ HA-Cys $\left(\mathrm{cR}_{10}\right)$-Ub-TZ upon $365 \mathrm{~nm}$ UV irradiation. Red represents enrichment (higher LFQ intensity $\left(\log _{2}\right)$ ), where lack of enrichment (lower LFQ intensity $\left(\log _{2}\right)$ ) is shown in purple. 


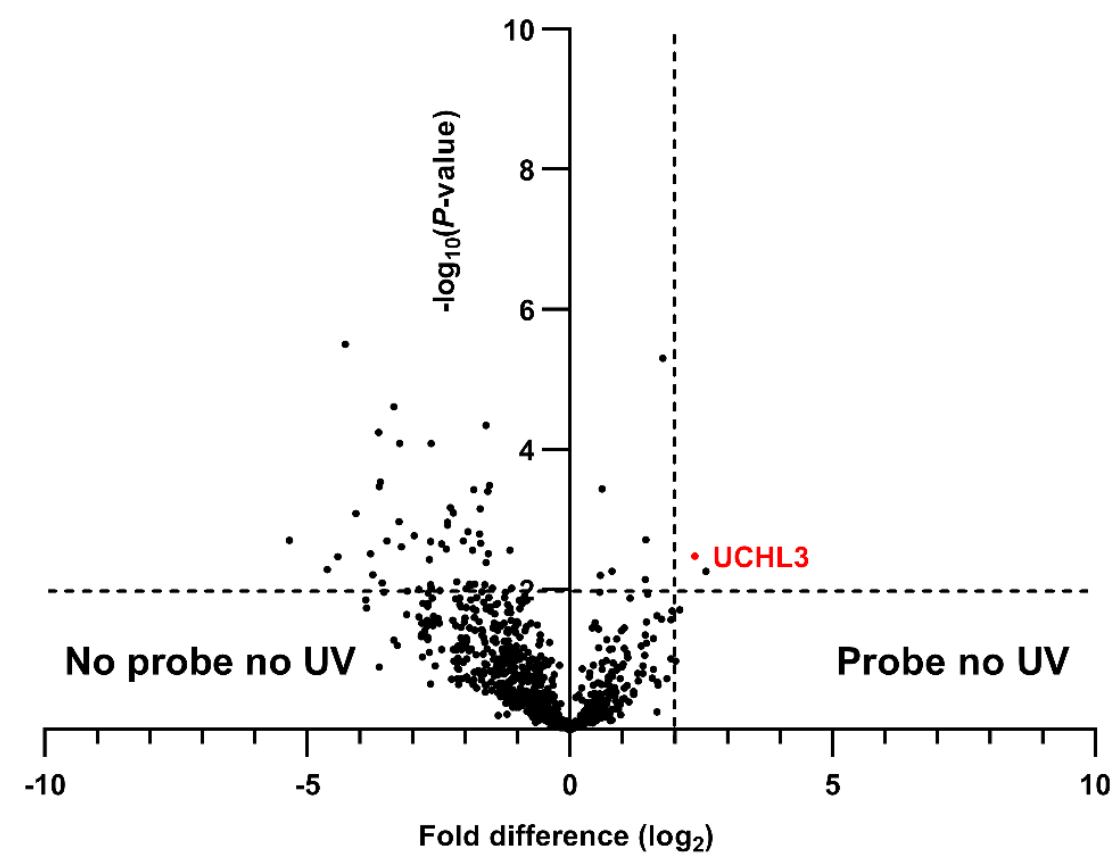

Figure S14: Volcano plot of protein groups pulled down in the absence of UV irradiation with $15 \mu \mathrm{M}$ HACys $\left(\mathrm{cR}_{10}\right)-\mathrm{Ub}-\mathrm{TZ}$ treatment versus control pulldown without probe. Significantly enriched DUB is colored and labeled as red. 
A

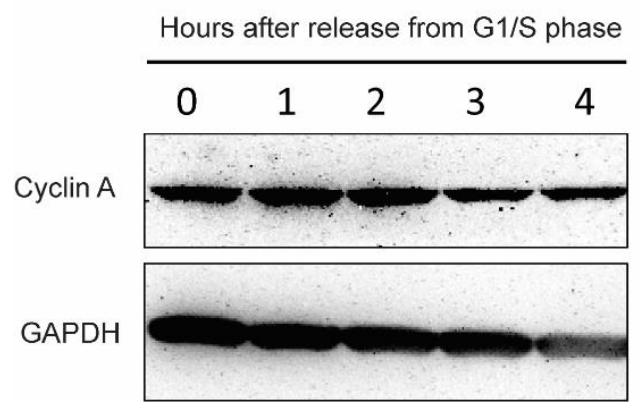

B

Hours after release from G2/M phase

$\begin{array}{llll}0 & 4 & 6 & 8\end{array}$

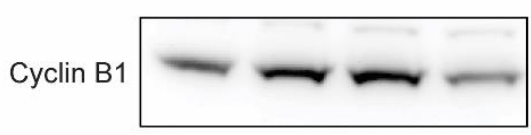

GAPDH

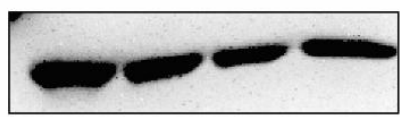

Figure S15: A) Expression levels of cyclin A and GAPDH in synchronized HeLa cells at indicated time points after release from G1/S phase block. B) Expression levels of cyclin B1 and GAPDH in synchronized HeLa cells at indicated time points after release from G2/M phase block. 


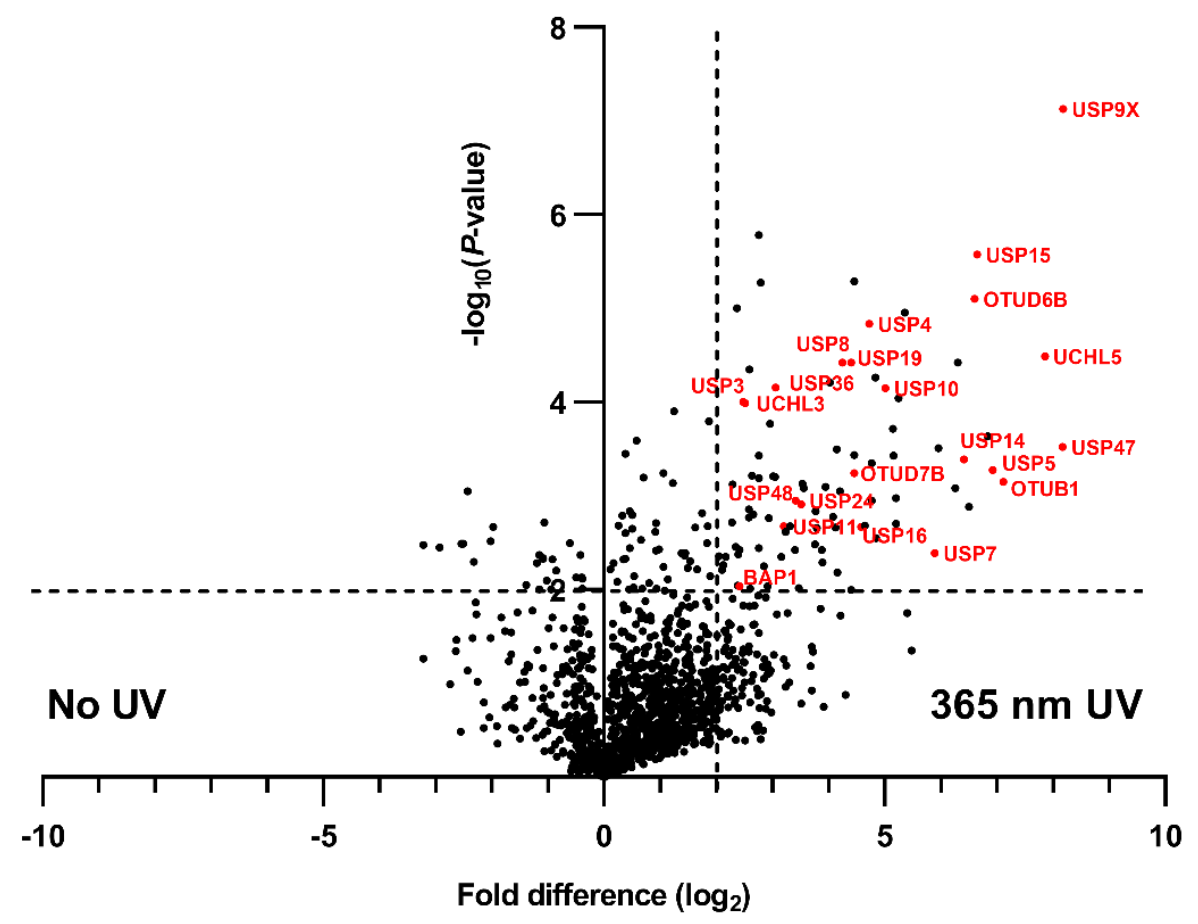

Figure S16: Volcano plot of pairwise comparison of protein groups pulled down in G1/S phase by $15 \mu \mathrm{M}$ HA-Cys $\left(\mathrm{cR}_{10}\right)-\mathrm{Ub}-\mathrm{TZ}$ with $365 \mathrm{~nm}$ UV irradiation relative to no UV irradiation. Significantly enriched DUBs are colored and labeled as red. 


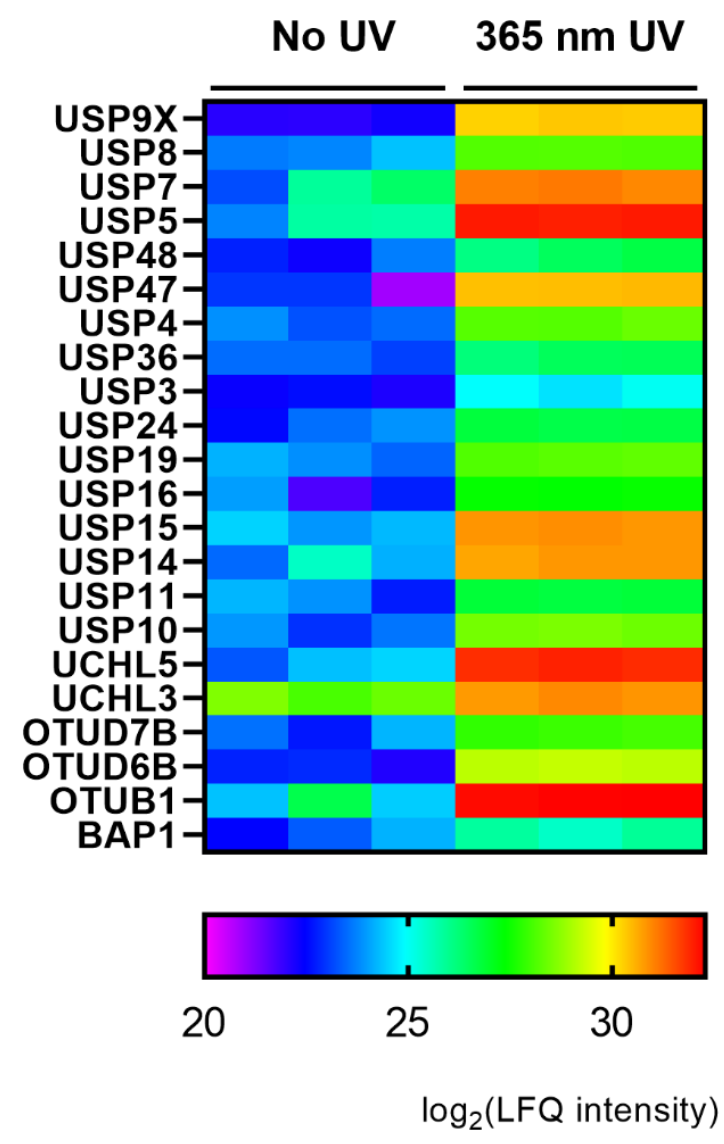

Figure S17: Heat map representing the LFQ intensity scores of G1/S phase DUBs significantly enriched by $15 \mu \mathrm{M}$ HA-Cys(cR 10$)-U b-T Z$ upon $365 \mathrm{~nm}$ UV irradiation. Red represents enrichment (higher LFQ intensity $\left.\left(\log _{2}\right)\right)$, where lack of enrichment (lower LFQ intensity $\left.\left(\log _{2}\right)\right)$ is shown in purple. 


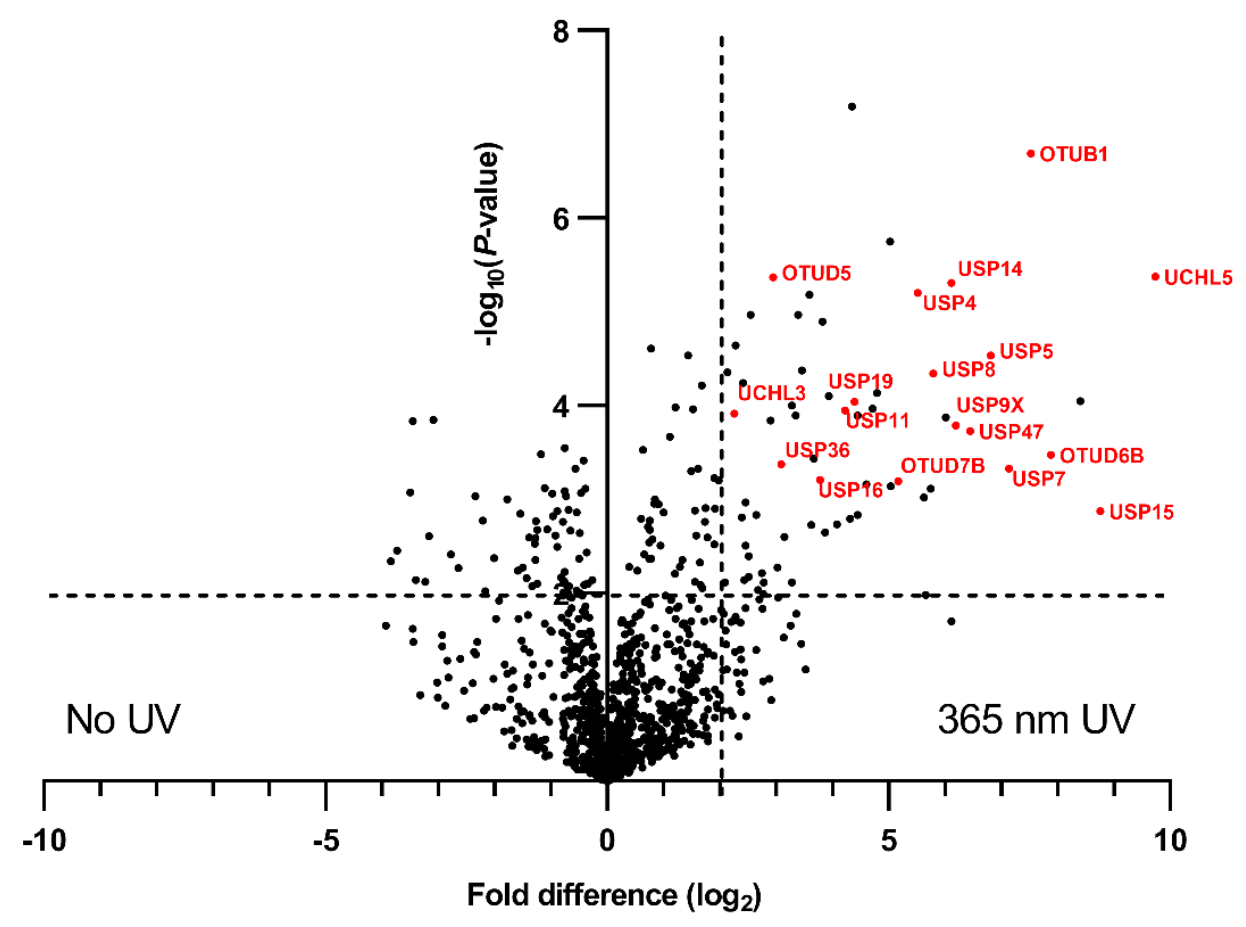

Figure S18: Volcano plot of pairwise comparison of protein groups pulled down in G2/M phase by HACys(cR 10$)-U b-T Z$ with $365 \mathrm{~nm}$ UV irradiation relative to no UV irradiation. Significantly enriched DUBs are colored and labeled as red. 


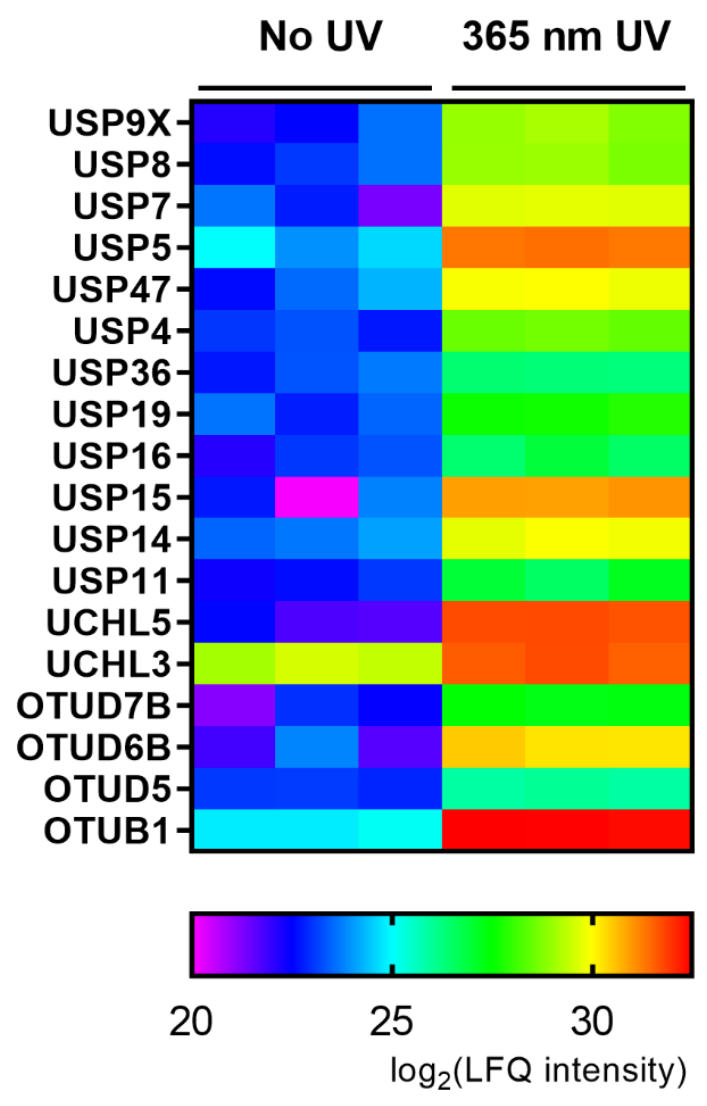

Figure S19: Heat map representing the LFQ intensity scores of G2/M phase DUBs significantly enriched by $15 \mu$ M HA-Cys $\left(\mathrm{cR}_{10}\right)$-Ub-TZ upon $365 \mathrm{~nm}$ UV irradiation. Red represents enrichment (higher LFQ intensity $\left.\left(\log _{2}\right)\right)$, where lack of enrichment (lower LFQ intensity $\left.\left(\log _{2}\right)\right)$ is shown in purple. 


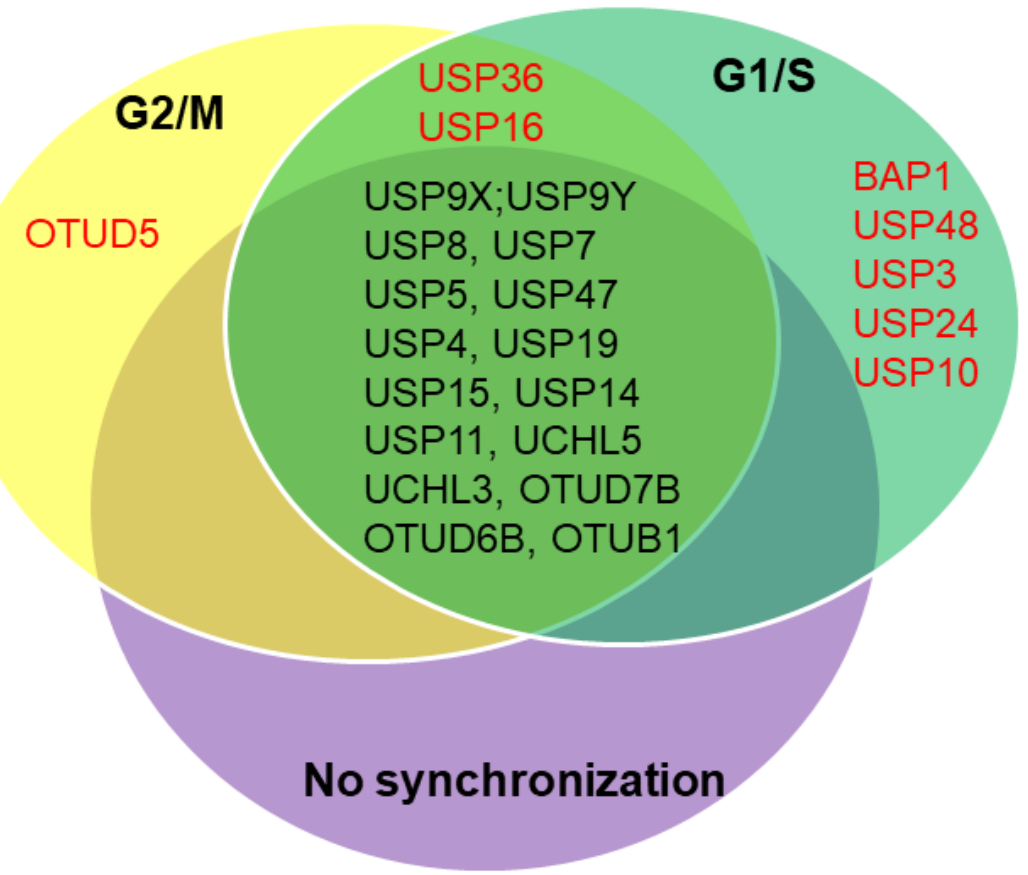

Figure S20: Intracellular proteome-wide DUB profiling by $15 \mu \mathrm{M}$ HA-Cys $\left(\mathrm{cR}_{10}\right)-\mathrm{Ub}-\mathrm{TZ}$ with $365 \mathrm{~nm} \mathrm{UV}$ irradiation comparing DUBs captured in different phases of cell cycle of HeLa cells and unsynchronized cells. 
Table S1. LFQ intensity scores for DUBs captured in HeLa cell using $15 \mu \mathrm{M}$ HA-Cys(cR $\left.{ }_{10}\right)-\mathrm{Ub}-\mathrm{TZ}$.

\begin{tabular}{|c|c|c|c|c|c|c|c|c|c|c|}
\hline \multirow[b]{2}{*}{ Gene Name } & \multicolumn{5}{|c|}{ No UV } & \multicolumn{5}{|c|}{$365 \mathrm{~nm}$ UV } \\
\hline & 1 & 2 & 3 & 4 & 5 & 1 & 2 & 3 & 4 & 5 \\
\hline USP9X;USP9Y & $\mathrm{NaN}$ & $\mathrm{NaN}$ & $\mathrm{NaN}$ & $\mathrm{NaN}$ & $\mathrm{NaN}$ & 28.3315 & 28.7999 & 28.8674 & 28.0177 & 27.8655 \\
\hline USP8 & $\mathrm{NaN}$ & $\mathrm{NaN}$ & $\mathrm{NaN}$ & $\mathrm{NaN}$ & $\mathrm{NaN}$ & 27.5821 & 27.9135 & 28.0068 & 24.8527 & 24.4727 \\
\hline USP7 & $\mathrm{NaN}$ & $\mathrm{NaN}$ & $\mathrm{NaN}$ & $\mathrm{NaN}$ & $\mathrm{NaN}$ & 29.0685 & 29.0024 & 29.1896 & 28.6109 & 28.7265 \\
\hline USP5 & 20.2356 & 22.126 & $\mathrm{NaN}$ & 23.0551 & $\mathrm{NaN}$ & 31.3299 & 31.8014 & 31.5739 & 29.9474 & 30.1598 \\
\hline USP48 & $\mathrm{NaN}$ & $\mathrm{NaN}$ & $\mathrm{NaN}$ & $\mathrm{NaN}$ & $\mathrm{NaN}$ & 23.6241 & 25.0739 & $\mathrm{NaN}$ & $\mathrm{NaN}$ & $\mathrm{NaN}$ \\
\hline USP47 & $\mathrm{NaN}$ & $\mathrm{NaN}$ & $\mathrm{NaN}$ & $\mathrm{NaN}$ & $\mathrm{NaN}$ & 28.8619 & 29.2001 & 29.059 & 27.6968 & 28.7979 \\
\hline USP4 & $\mathrm{NaN}$ & $\mathrm{NaN}$ & $\mathrm{NaN}$ & $\mathrm{NaN}$ & $\mathrm{NaN}$ & 28.0277 & 28.2591 & 27.813 & 24.6895 & 25.326 \\
\hline USP36 & $\mathrm{NaN}$ & $\mathrm{NaN}$ & $\mathrm{NaN}$ & $\mathrm{NaN}$ & $\mathrm{NaN}$ & 24.413 & 26.8809 & 25.8991 & $\mathrm{NaN}$ & $\mathrm{NaN}$ \\
\hline USP32 & $\mathrm{NaN}$ & $\mathrm{NaN}$ & $\mathrm{NaN}$ & $\mathrm{NaN}$ & $\mathrm{NaN}$ & 22.6995 & $\mathrm{NaN}$ & $\mathrm{NaN}$ & $\mathrm{NaN}$ & $\mathrm{NaN}$ \\
\hline USP3 & $\mathrm{NaN}$ & $\mathrm{NaN}$ & $\mathrm{NaN}$ & $\mathrm{NaN}$ & $\mathrm{NaN}$ & $\mathrm{NaN}$ & 25.4547 & $\mathrm{NaN}$ & $\mathrm{NaN}$ & $\mathrm{NaN}$ \\
\hline USP24 & $\mathrm{NaN}$ & $\mathrm{NaN}$ & $\mathrm{NaN}$ & $\mathrm{NaN}$ & $\mathrm{NaN}$ & 24.5104 & 24.5575 & 24.4334 & $\mathrm{NaN}$ & $\mathrm{NaN}$ \\
\hline USP19 & $\mathrm{NaN}$ & $\mathrm{NaN}$ & $\mathrm{NaN}$ & $\mathrm{NaN}$ & $\mathrm{NaN}$ & 27.8889 & 27.9596 & 27.6817 & 26.1838 & 26.9584 \\
\hline USP16 & $\mathrm{NaN}$ & $\mathrm{NaN}$ & $\mathrm{NaN}$ & $\mathrm{NaN}$ & $\mathrm{NaN}$ & 26.3284 & 26.8476 & 26.107 & $\mathrm{NaN}$ & 25.837 \\
\hline USP15 & $\mathrm{NaN}$ & $\mathrm{NaN}$ & $\mathrm{NaN}$ & $\mathrm{NaN}$ & $\mathrm{NaN}$ & 30.5241 & 30.8309 & 30.71 & 29.1151 & 29.5596 \\
\hline USP14 & $\mathrm{NaN}$ & $\mathrm{NaN}$ & $\mathrm{NaN}$ & 21.3546 & 22.5708 & 30.189 & 30.3644 & 30.2598 & 29.1904 & 29.4062 \\
\hline USP11 & $\mathrm{NaN}$ & $\mathrm{NaN}$ & $\mathrm{NaN}$ & $\mathrm{NaN}$ & $\mathrm{NaN}$ & 27.545 & 27.5541 & 27.488 & $\mathrm{NaN}$ & $\mathrm{NaN}$ \\
\hline USP10 & $\mathrm{NaN}$ & $\mathrm{NaN}$ & $\mathrm{NaN}$ & $\mathrm{NaN}$ & $\mathrm{NaN}$ & 24.8332 & 25.2595 & 27.0565 & 24.2849 & $\mathrm{NaN}$ \\
\hline UCHL5 & $\mathrm{NaN}$ & $\mathrm{NaN}$ & $\mathrm{NaN}$ & $\mathrm{NaN}$ & $\mathrm{NaN}$ & 30.5535 & 30.5978 & 31.2686 & 31.3588 & 31.2413 \\
\hline UCHL3 & 25.0648 & 25.6011 & 25.7311 & 26.1971 & 24.7534 & 30.6053 & 30.6175 & 30.198 & 30.124 & 30.3168 \\
\hline OTUD7B & $\mathrm{NaN}$ & $\mathrm{NaN}$ & $\mathrm{NaN}$ & $\mathrm{NaN}$ & $\mathrm{NaN}$ & 24.5043 & 24.1319 & 23.8216 & 27.3838 & 26.6543 \\
\hline OTUD6B & $\mathrm{NaN}$ & $\mathrm{NaN}$ & 21.7102 & $\mathrm{NaN}$ & $\mathrm{NaN}$ & 25.1818 & 23.6787 & 29.1847 & 29.5897 & 29.3455 \\
\hline OTUD5 & $\mathrm{NaN}$ & $\mathrm{NaN}$ & $\mathrm{NaN}$ & $\mathrm{NaN}$ & $\mathrm{NaN}$ & $\mathrm{NaN}$ & $\mathrm{NaN}$ & $\mathrm{NaN}$ & $\mathrm{NaN}$ & 25.5665 \\
\hline OTUB1 & 23.204 & $\mathrm{NaN}$ & 24.8155 & $\mathrm{NaN}$ & $\mathrm{NaN}$ & 31.1374 & 31.2886 & 31.9004 & 32.07 & 31.8336 \\
\hline
\end{tabular}

$(\mathrm{NaN})$, protein groups not detected. 
Table S2. LFQ intensity scores for proteins other than DUBs significantly enriched in HeLa cell using 15 $\mu \mathrm{M}$ HA-Cys(cR 10$)-U b-T Z$.

\begin{tabular}{|c|c|c|c|c|c|c|c|c|c|c|}
\hline \multirow[b]{2}{*}{ Gene name } & \multicolumn{5}{|c|}{ No UV } & \multicolumn{5}{|c|}{$365 \mathrm{~nm}$ UV } \\
\hline & 1 & 2 & 3 & 4 & 5 & 1 & 2 & 3 & 4 & 5 \\
\hline VDAC3 & $\mathrm{NaN}$ & $\mathrm{NaN}$ & 24.1911 & 26.0451 & $\mathrm{NaN}$ & 25.5378 & 25.6446 & 26.7551 & 27.1071 & 27.2153 \\
\hline TXNRD1 & $\mathrm{NaN}$ & $\mathrm{NaN}$ & 26.4228 & 26.4205 & 24.383 & 29.5149 & 29.8737 & 31.2127 & 31.1446 & 31.2132 \\
\hline TXNL1 & $\mathrm{NaN}$ & $\mathrm{NaN}$ & $\mathrm{NaN}$ & $\mathrm{NaN}$ & $\mathrm{NaN}$ & 26.239 & 24.8414 & 26.8243 & 25.9941 & 26.359 \\
\hline TUBG1;TUBG2 & $\mathrm{NaN}$ & $\mathrm{NaN}$ & $\mathrm{NaN}$ & $\mathrm{NaN}$ & $\mathrm{NaN}$ & $\mathrm{NaN}$ & $\mathrm{NaN}$ & 25.9719 & 25.2844 & 25.8985 \\
\hline RPS9 & $\mathrm{NaN}$ & $\mathrm{NaN}$ & 24.8518 & 29.2159 & $\mathrm{NaN}$ & 28.6813 & 29.0113 & 29.5475 & 29.7339 & 29.5761 \\
\hline RPS15A & $\mathrm{NaN}$ & $\mathrm{NaN}$ & $\mathrm{NaN}$ & 29.4472 & $\mathrm{NaN}$ & 28.9104 & 28.9857 & 29.3549 & 29.3746 & 29.4466 \\
\hline RPL28 & $\mathrm{NaN}$ & 25.272 & 25.096 & 27.3829 & 24.1306 & 27.2031 & 27.2147 & 27.8742 & 27.6196 & 27.8021 \\
\hline RPL24 & $\mathrm{NaN}$ & $\mathrm{NaN}$ & 25.5913 & 26.9917 & 22.221 & 27.4561 & 29.5249 & 28.9248 & 29.0904 & 29.1317 \\
\hline RAP2C & $\mathrm{NaN}$ & $\mathrm{NaN}$ & $\mathrm{NaN}$ & $\mathrm{NaN}$ & $\mathrm{NaN}$ & 24.7452 & $\mathrm{NaN}$ & 24.8806 & 24.8578 & 25.2572 \\
\hline RAB1s & $\mathrm{NaN}$ & $\mathrm{NaN}$ & $\mathrm{NaN}$ & 28.2238 & $\mathrm{NaN}$ & 27.543 & 27.0064 & 28.5305 & 28.7422 & 28.5595 \\
\hline PYGL & $\mathrm{NaN}$ & $\mathrm{NaN}$ & $\mathrm{NaN}$ & 24.4705 & $\mathrm{NaN}$ & 24.2626 & $\mathrm{NaN}$ & 24.7085 & 26.0089 & 25.1663 \\
\hline PSMD5 & $\mathrm{NaN}$ & $\mathrm{NaN}$ & $\mathrm{NaN}$ & 24.4639 & $\mathrm{NaN}$ & 24.7451 & 24.5933 & 25.2666 & 25.6942 & 26.2348 \\
\hline PSMD3 & $\mathrm{NaN}$ & $\mathrm{NaN}$ & 24.6898 & 24.9453 & $\mathrm{NaN}$ & 26.0478 & 24.6055 & 27.1184 & 26.7428 & 27.0417 \\
\hline PSMD2 & $\mathrm{NaN}$ & $\mathrm{NaN}$ & 24.3679 & 26.3623 & $\mathrm{NaN}$ & 27.4101 & 28.8331 & 29.6791 & 30.4561 & 29.9177 \\
\hline PSMD12 & $\mathrm{NaN}$ & $\mathrm{NaN}$ & $\mathrm{NaN}$ & 26.0903 & $\mathrm{NaN}$ & 26.4866 & 25.1397 & 27.9649 & 28.4647 & 28.4363 \\
\hline PSMD11 & $\mathrm{NaN}$ & $\mathrm{NaN}$ & 24.5586 & $\mathrm{NaN}$ & $\mathrm{NaN}$ & 24.9424 & 26.6761 & 27.824 & 28.751 & 28.4815 \\
\hline PSMD1 & $\mathrm{NaN}$ & $\mathrm{NaN}$ & $\mathrm{NaN}$ & $\mathrm{NaN}$ & 22.5961 & 27.6909 & 28.2707 & 28.7738 & 28.8057 & 28.9372 \\
\hline PSMC6 & $\mathrm{NaN}$ & $\mathrm{NaN}$ & $\mathrm{NaN}$ & $\mathrm{NaN}$ & $\mathrm{NaN}$ & 24.8715 & 27.4638 & 28.8751 & 29.5989 & 29.1026 \\
\hline PSMC5 & $\mathrm{NaN}$ & $\mathrm{NaN}$ & 24.2692 & 26.6947 & 23.3601 & 29.1465 & 29.2441 & 29.8786 & 29.8263 & 30.0863 \\
\hline PSMC4 & $\mathrm{NaN}$ & 22.2232 & 21.2669 & 23.1635 & $\mathrm{NaN}$ & 28.2573 & 27.9877 & 28.9581 & 29.5309 & 29.3455 \\
\hline PSMC3 & $\mathrm{NaN}$ & $\mathrm{NaN}$ & $\mathrm{NaN}$ & 25.0519 & $\mathrm{NaN}$ & 28.2949 & 28.5933 & 29.418 & 29.2574 & 29.3574 \\
\hline PSMC2 & $\mathrm{NaN}$ & $\mathrm{NaN}$ & $\mathrm{NaN}$ & 25.8201 & $\mathrm{NaN}$ & 28.9473 & 29.3472 & 29.4719 & 29.9304 & 29.7466 \\
\hline PSMC1 & $\mathrm{NaN}$ & $\mathrm{NaN}$ & $\mathrm{NaN}$ & 24.3122 & $\mathrm{NaN}$ & 28.2992 & 28.9927 & 28.48 & 29.63 & 29.1337 \\
\hline PDLIM5 & $\mathrm{NaN}$ & $\mathrm{NaN}$ & $\mathrm{NaN}$ & $\mathrm{NaN}$ & $\mathrm{NaN}$ & 24.0299 & 23.742 & 25.4015 & 25.3455 & 25.3096 \\
\hline PDCD6IP & $\mathrm{NaN}$ & $\mathrm{NaN}$ & $\mathrm{NaN}$ & 24.6357 & 23.7052 & 24.8547 & 25.0669 & 26.5999 & 25.4366 & 25.1956 \\
\hline PABPC1;C3 & 23.3585 & 23.9333 & 24.1752 & 26.6471 & 24.7792 & 26.5504 & 26.7457 & 27.3759 & 26.4746 & 26.4159 \\
\hline NUMA1 & $\mathrm{NaN}$ & $\mathrm{NaN}$ & $\mathrm{NaN}$ & 24.9626 & $\mathrm{NaN}$ & 26.7693 & 27.0973 & 26.8749 & 28.1156 & 27.8927 \\
\hline MGST1 & $\mathrm{NaN}$ & $\mathrm{NaN}$ & $\mathrm{NaN}$ & $\mathrm{NaN}$ & $\mathrm{NaN}$ & 24.495 & $\mathrm{NaN}$ & 25.3089 & 25.1222 & 25.2498 \\
\hline MARS & 23.4149 & $\mathrm{NaN}$ & $\mathrm{NaN}$ & 22.6214 & $\mathrm{NaN}$ & 24.2382 & 26.4202 & 25.3701 & 27.4579 & 26.5003 \\
\hline MAGT1 & $\mathrm{NaN}$ & $\mathrm{NaN}$ & $\mathrm{NaN}$ & $\mathrm{NaN}$ & $\mathrm{NaN}$ & $\mathrm{NaN}$ & $\mathrm{NaN}$ & 23.9187 & 24.703 & 24.4729 \\
\hline IPO5 & $\mathrm{NaN}$ & $\mathrm{NaN}$ & 22.8805 & $\mathrm{NaN}$ & $\mathrm{NaN}$ & 23.4608 & 26.397 & 26.9349 & 27.7489 & 27.1534 \\
\hline IGKV4-1 & $\mathrm{NaN}$ & $\mathrm{NaN}$ & $\mathrm{NaN}$ & 27.7336 & $\mathrm{NaN}$ & 27.1822 & 27.6874 & 27.8236 & 28.5357 & 27.9662 \\
\hline ERLIN2 & $\mathrm{NaN}$ & $\mathrm{NaN}$ & $\mathrm{NaN}$ & $\mathrm{NaN}$ & $\mathrm{NaN}$ & $\mathrm{NaN}$ & 23.4575 & 25.202 & $\mathrm{NaN}$ & 25.6952 \\
\hline EPPK1 & $\mathrm{NaN}$ & $\mathrm{NaN}$ & 26.492 & $\mathrm{NaN}$ & 25.2328 & 26.0604 & 27.3481 & 27.8788 & 28.4958 & 27.4981 \\
\hline EIF3B & $\mathrm{NaN}$ & $\mathrm{NaN}$ & $\mathrm{NaN}$ & 24.2068 & $\mathrm{NaN}$ & 24.6114 & 24.3998 & 26.1814 & 27.2162 & 25.5444 \\
\hline AUP1 & $\mathrm{NaN}$ & $\mathrm{NaN}$ & $\mathrm{NaN}$ & $\mathrm{NaN}$ & $\mathrm{NaN}$ & 25.7209 & 25.7907 & 27.3528 & 27.4678 & 27.1832 \\
\hline ATL3 & 20.9944 & $\mathrm{NaN}$ & $\mathrm{NaN}$ & 23.2999 & $\mathrm{NaN}$ & $\mathrm{NaN}$ & $\mathrm{NaN}$ & 25.9572 & 27.1395 & 26.9036 \\
\hline ATAD3A;3C & $\mathrm{NaN}$ & $\mathrm{NaN}$ & 22.3204 & 28.282 & 21.7979 & 27.3405 & 27.4363 & 28.6142 & 29.049 & 28.9578 \\
\hline AIMP1 & $\mathrm{NaN}$ & $\mathrm{NaN}$ & $\mathrm{NaN}$ & $\mathrm{NaN}$ & $\mathrm{NaN}$ & 25.3229 & 26.6795 & 25.8377 & 26.2572 & 26.7655 \\
\hline
\end{tabular}

$(\mathrm{NaN})$, protein groups not detected. 
Table S3. Pairwise comparison of fold difference and $P$-value $\left(-\log _{10}\right)$ for DUBs captured in HeLa cells at different time points following the release from G1/S phase using $15 \mu \mathrm{M}$ HA-Cys $\left(\mathrm{cR}_{10}\right)-\mathrm{Ub}-\mathrm{TZ}$.

\begin{tabular}{|c|c|c|c|c|c|c|}
\hline \multirow[b]{2}{*}{ Gene name } & \multicolumn{2}{|c|}{$\begin{array}{c}1 \mathrm{~h} / 0 \mathrm{~h} \text { following the release from } \\
\text { G1/s }\end{array}$} & \multicolumn{2}{|c|}{$\begin{array}{c}4 \mathrm{~h} / 0 \mathrm{~h} \text { following the release from } \\
\text { G1/s }\end{array}$} & \multicolumn{2}{|c|}{$\begin{array}{c}4 \mathrm{~h} / 1 \mathrm{~h} \text { following the release from } \\
\text { G1/s }\end{array}$} \\
\hline & fold difference & $P$ value $\left(-\log _{10}\right)$ & fold difference & $P$ value $\left(-\log _{10}\right)$ & fold difference & $P$ value $\left(-\log _{10}\right)$ \\
\hline OTUB1 & 0.88 & 0.18 & 0.52 & 1.34 & 0.58 & 1.64 \\
\hline OTUD6B & 0.95 & 0.07 & 0.54 & 1.23 & 0.57 & 1.75 \\
\hline OTUD7B & 1.02 & 0.02 & 0.74 & 0.66 & 0.73 & 0.71 \\
\hline UCHL3 & 0.95 & 0.09 & 0.72 & 0.85 & 0.75 & 1.48 \\
\hline UCHL5 & 0.98 & 0.03 & 0.72 & 1.22 & 0.73 & 1.29 \\
\hline USP10 & 1.23 & 0.21 & 0.33 & 1.99 & 0.27 & 1.55 \\
\hline USP11 & 1.12 & 0.11 & 1.09 & 0.08 & 0.97 & 0.03 \\
\hline USP14 & 1.85 & 1.08 & 1.11 & 0.14 & 0.60 & 0.78 \\
\hline USP15 & 1.45 & 0.55 & 1.23 & 0.27 & 0.85 & 0.65 \\
\hline USP16 & 1.11 & 0.09 & 0.52 & 0.85 & 0.47 & 1.75 \\
\hline USP19 & 4.21 & 1.43 & 2.45 & 0.62 & 0.58 & 0.61 \\
\hline USP4 & 1.01 & 0.00 & 0.46 & 0.55 & 0.45 & 0.60 \\
\hline USP47 & 1.53 & 0.66 & 1.12 & 0.15 & 0.73 & 0.42 \\
\hline USP5 & 0.97 & 0.08 & 0.90 & 0.51 & 0.93 & 0.27 \\
\hline USP7 & 1.22 & 0.35 & 0.84 & 0.33 & 0.69 & 1.08 \\
\hline USP8 & 1.10 & 0.15 & 0.65 & 0.85 & 0.59 & 1.09 \\
\hline USP9X;USP9Y & 1.81 & 0.70 & 0.96 & 0.04 & 0.53 & 1.22 \\
\hline
\end{tabular}

Note: When protein groups were not detected by MaxQuant analysis (NaN), LFQ value was imputed by Perseus for calculation of fold-difference between pulldowns (see Supplemental Methods), which is the case for USP16 not being detected in $4 \mathrm{~h}$. 


\section{Supplemental Methods}

Plasmid Construction and Gene Cloning. The yeast $\mathrm{Ub}_{1-75}$ gene was mutated using QuikChange polymerase chain reaction (PCR) to generate the humanized $\mathrm{Ub}_{1-75}(\mathrm{~S} 19 \mathrm{P}, \mathrm{D} 24 \mathrm{E}$, and $\mathrm{S} 28 \mathrm{~A})$ and used throughout this work. The generation of HA-Cys-Ub ${ }_{1-75}$ is described in previous publication. ${ }^{[1]}$

Protein Expression and Purification. Ubiquitin was expressed and purified as described below. HA-Cys$\mathrm{Ub}_{1-75}$ plasmid was transformed into BL21(DE3) cells and cultured at $37{ }^{\circ} \mathrm{C}$ until $\mathrm{OD}_{600}$ reached 0.3-0.4. The incubation temperature was decreased to $16^{\circ} \mathrm{C}$ until $\mathrm{OD}_{600}$ reached $0.4-0.6$. Then, protein expression was induced with $1 \mathrm{mM}$ IPTG. Cells were cultured for an additional $15-20 \mathrm{~h}$ at $16{ }^{\circ} \mathrm{C}$ after the induction and harvested by centrifugation at $6,000 \mathrm{rpm}$ for $10 \mathrm{~min}$ at $4{ }^{\circ} \mathrm{C}$. Cells expressing HA-Cys-Ub were sonicated in lysis buffer containing $20 \mathrm{mM}$ Tris (pH 7.5), $200 \mathrm{mM} \mathrm{NaCl}, 5 \%$ glycerol and $1 \mathrm{mM}$ EDTA, 1 $\mathrm{mM}$ PMSF, and centrifuged at 6,000 rpm. The cell free extract was incubated chitin resin (New England Biolabs, Ipswich, MA) overnight at $4{ }^{\circ} \mathrm{C}$. After removal of unbound proteins via centrifugation $(2,000 \mathrm{rpm}$ at $4{ }^{\circ} \mathrm{C}$ ), the resin was first washed with a high salt buffer containing $20 \mathrm{mM}$ Tris ( $\left.\mathrm{pH} 7.5\right), 0.5 \mathrm{M} \mathrm{NaCl}, 5 \%$ glycerol, 1 mM EDTA, followed by a low salt buffer wash with $20 \mathrm{mM}$ MES (pH 6.5), $100 \mathrm{mM} \mathrm{NaCl}$. The washed resin was then incubated with cleavage buffer containing $20 \mathrm{mM}$ MES (pH 6.5), $100 \mathrm{mM} \mathrm{NaCl}, 80$ mM MESNA for $15 \mathrm{~h}$ at $4{ }^{\circ} \mathrm{C}$. Protein was then eluted and concentrated using Amicon Ultra-15 Centrifugal Filter Units (Thermo Fisher Scientific, Waltham, MA). The purity of proteins was estimated to be $90 \%$ or greater by SDS-PAGE gel analysis with Coomassie Blue staining. Bradford assay was used to determine the concentration of the purified protein and protein sample was flash frozen and stored at $-80{ }^{\circ} \mathrm{C}$. USP2$\mathrm{CD}, \mathrm{UCHL} 1$ and UCHL3 were expressed and purified as previously described. ${ }^{[2]}$

Mammalian Cell Culture. HeLa cell line (ATCC CCL-2) was cultured in RPMI-1640 Medium (Thermo Fisher Scientific Inc., Waltham, MA) supplemented with $10 \%$ FBS. Cells were maintained at $37^{\circ} \mathrm{C}$ and $5 \%$ $\mathrm{CO}_{2}$ in a humidified incubator.

Immunoblotting Analysis of DUB Labeling by Ubiquitin Probes. HeLa cells were plated in Corning Costar Flat Bottom Cell Culture 6-well plates (Mediatech, Inc., Manassas, VA) at 50\% confluence and allowed to adhere for $12 \mathrm{~h}$ in RPMI-1640 medium supplemented with $10 \% \mathrm{FBS}$ at $37{ }^{\circ} \mathrm{C}$ and $5 \% \mathrm{CO}_{2}$. Cells were treated with $15 \mu \mathrm{M}$ of HA-Cys(cR $\left(\mathrm{CR}_{10}\right)-\mathrm{Ub}-\mathrm{TZ}$ for $4 \mathrm{~h}$ at $37^{\circ} \mathrm{C}$ at $5 \% \mathrm{CO}_{2}$ in the same medium. Post probe treatment, $0.25 \%$ trypsin, $0.1 \%$ EDTA in HBSS buffer without calcium, magnesium, and sodium bicarbonate (Mediatech, Inc., Manassas, VA) was added to cells and allowed to incubate for 3 min at room temperature. After trypsin solution was removed, cells were washed three times with cold DPBS buffer (Dulbecco's Phosphate-Buffered Salt solution) (Mediatech, Inc., Manassas, VA). Cells were then harvested and washed with cold DPBS and used immediately for the following experiments or stored at $-80^{\circ} \mathrm{C}$. 
Cell lysate for immunoblotting was generated according to previous publication. ${ }^{[1]} 40 \mu \mathrm{g}$ cell lysate was incubate with $15 \mu \mathrm{M}$ probe at $37^{\circ} \mathrm{C}$ for $2 \mathrm{~h}$. After incubation samples were quenched using a $6 \mathrm{X}$ gel loading dye (35 mM Tris, 10\% SDS, 30\% glycerol and 9.3\% DTT, pH 6.8) and resolved on a 12\% reducing SDS-PAGE gel followed by transfer to a PDVF membrane (Thermo Fisher Scientific Inc., Waltham, MA). The membrane was immunoblotted with an anti-HA antibody. HRP-conjugated anti-mouse antibody was used as the secondary antibody. GAPDH protein level was utilized as a loading control and detected using an anti-GAPDH antibody. HRP-conjugated anti-rabbit antibody was used as the secondary antibody for GAPDH. ECL Western blotting substrate (Thermo Fisher Scientific Inc., Waltham, MA) was used to detect the immunoblotting signal.

Pulldown and Mass Spectrometry Analysis. For intracellular proteome-wide protein profiling using MSbased LFQ analysis, $200 \mu \mathrm{g}$ cell lysate generated from the HA-Cys(cR 10$)-\mathrm{Ub}-\mathrm{TZ}$ treated HeLa cells as described above was incubated with $100 \mu \mathrm{L}$ anti-HA magnetic beads in RIPA buffer supplemented with 1X Complete Protease Cocktail Inhibitor at room temperature for $2 \mathrm{~h}$. Unbound proteins were removed by aspiration. The remaining anti-HA magnetic beads were washed 3 times with Tris-buffered saline, $0.1 \%$ Tween-20 (TBST). The enriched proteins by HA beads were eluted with $100 \mu \mathrm{L} 50 \mathrm{mM} \mathrm{NaOH}$. Eluate was neutralized to $\mathrm{pH} 8$ using $100 \mu \mathrm{L} 1 \mathrm{M} \mathrm{NH}_{4} \mathrm{HCO}_{3}$ solution, and adjusted to have $0.1 \%$ SDS. Then the protein solution was reduced with $20 \mathrm{mM}$ DTT at $60{ }^{\circ} \mathrm{C}$ water bath for $1 \mathrm{~h}$. The sample was then alkylated with 40 $\mathrm{mM}$ iodoacetamide at room temperature for $30 \mathrm{~min}$ with protection from light. The alkylation reaction was quenched by adding $10 \mathrm{mM}$ DTT. Then, $1.2 \mathrm{~mL}$ cold acetone was added to the mixture to precipitate proteins from the solution at $-20{ }^{\circ} \mathrm{C}$ overnight. The mixture was centrifuged at $14,000 \mathrm{rpm}$ for $10 \mathrm{~min}$ to collect protein pellet at the bottom of the tube. The protein pellet was then dissolved in $200 \mu \mathrm{L} 100 \mathrm{mM}$ $\mathrm{NH}_{4} \mathrm{HCO}_{3}$ and digested with $2 \mu \mathrm{g}$ of trypsin at $37{ }^{\circ} \mathrm{C}$ for $18 \mathrm{~h}$. Tryptic digestion was quenched by $0.1 \%$ formic acid. Centrifugation at 13,000 $\mathrm{g}$ at room temperature for $10 \mathrm{~min}$ was used to remove residual precipitation. Digested peptide sample was desalted with C18 zip tip and lyophilized prior to LC-MS/MS analysis.

Lyophilized trypsin digested samples were dissolved in $0.1 \%$ formic acid in $\mathrm{ddH}_{2} \mathrm{O}$ prior to LCMS/MS analysis using a nano UHPLC column (15 cm long, $75 \mu \mathrm{m}$ inner diameter, $3 \mu \mathrm{m}$ C18 resin, Thermo Fisher Scientific, Waltham, MA)) connected to Orbitrap Q-Exactive operated in a positive polarity mode and collision induced dissociation (Thermo Fisher Scentific, Waltham, MA) with a nano-electrospray ion source. A linear gradient of 5\% - 60\% acetonitrile in water with $0.1 \%$ formic acid for 150 minutes was used to separate peptides at a constant flow rate of $200 \mathrm{~nL} / \mathrm{min}$. The MS system operates in a data-dependent 
mode with MS/MS scan of the six most abundant peaks from a full MS scan, which was acquired between 300 to $1800 \mathrm{~m} / \mathrm{z}$ with a resolution of 60,000 .

MaxQuant software version 1.4.0.6 and its Label-Free Quantification (LFQ) module were used to quantify enriched proteins as described previously. ${ }^{[1]}$ When protein groups were not detected by MaxQuant analysis (NaN), an imputation by Perseus (version 1.6.1.3) was used to generate LFQ values based on normal distribution of valid LFQ values for calculation of fold-difference between pulldowns. Two-sample $t$-test was performed using the default parameters in Perseus. To generate the volcano plots, the $-\log _{10}(P$ value) and $\log _{2}$ (fold difference of LFQ values between paired samples) were plotted in GraphPad Prism (version 8).

Double Thymidine and Nocodazole Synchronization of HeLa Cells. To synchronize cells to G1/S phase, Hela cells were seeded at approximately 40\% confluency in RPMI-1640 Medium supplemented with 10\% FBS. The Corning ${ }^{\mathrm{TM}}$ Costar $^{\mathrm{TM}}$ Flat Bottom Cell Culture 6-well plates (Mediatech, Inc., Manassas, VA) were used. Cells were incubated at $37^{\circ} \mathrm{C}$ and $5 \% \mathrm{CO}_{2}$ for approximately $24 \mathrm{~h}$. RPMI-1640 medium supplemented with $2.0 \mathrm{mM}$ thymidine (MilliporeSigma Inc., Burlington, MA) was used to replace the cell culture medium and cells were incubated at $37{ }^{\circ} \mathrm{C}$ and $5 \% \mathrm{CO}_{2}$ for another $12 \mathrm{~h}$. The medium was removed and cells were washed three times by DPBS buffer. Fresh RPMI-1640 medium was added to the cells and incubated for $12 \mathrm{~h}$ at $37^{\circ} \mathrm{C}$ and $5 \% \mathrm{CO}_{2}$. This thymidine-block procedure was repeated one more time. Following this double thymidine block procedure, cells in RPMI-1640 medium supplemented with $2.0 \mathrm{mM}$ thymidine were treated with $\mathrm{HA}-\mathrm{Cys}\left(\mathrm{cR}_{10}\right)-\mathrm{Ub}-\mathrm{TZ}$ probe as described above.

To synchronize cells to G2/M phase, Hela cells were seeded at approximately $60 \%$ confluency in RPMI-1640 medium using Corning ${ }^{\mathrm{TM}}$ Costar $^{\mathrm{TM}}$ Flat Bottom Cell Culture 6-well plates (Mediatech, Inc., Manassas, VA). Cells were incubated at $37^{\circ} \mathrm{C}$ and $5 \% \mathrm{CO}_{2}$ for approximately $24 \mathrm{~h}$. RPMI-1640 medium supplemented with $0.5 \mu \mathrm{g} / \mathrm{mL}$ nocodazole (MilliporeSigma Inc., Burlington, MA) was used to replace the cell culture medium and cells were incubated at $37{ }^{\circ} \mathrm{C}$ and $5 \% \mathrm{CO}_{2}$ for another $12 \mathrm{~h}$. Cells in RPMI-1640 medium supplemented with $0.5 \mu \mathrm{g} / \mathrm{mL}$ nocodazole were then treated with $\mathrm{HA}-\mathrm{Cys}\left(\mathrm{cR}_{10}\right)-\mathrm{Ub}-\mathrm{TZ}$ probe as described above.

Time Dependent Pulldown Following the Release of HeLa Cells from G1/S Phase. HeLa cells were synchronized to G1/S phase as described above. Then, HeLa cells were incubated with $15 \mu \mathrm{M}$ HACys(cR 10 )-Ub-TZ probe in RPMI1640 media containing $2 \mathrm{mM}$ thymidine at $37{ }^{\circ} \mathrm{C}$ and $5 \% \mathrm{CO}_{2}$ for $4 \mathrm{~h}$. Cells were then rinsed with a trypsin-EDTA solution followed by several cold DPBS wash to remove untransduced probe. For the $0 \mathrm{~h}$ time point treatment, the HeLa cells were irradiated immediately with 365 $\mathrm{nm}$ UV for $15 \mathrm{~min}$ in cold DPBS buffer. For the 1 and $4 \mathrm{~h}$ time point treatment, the HeLa cells were 
incubated with fresh RPMI1640 media without thymidine for $1 \mathrm{~h}$ and $4 \mathrm{~h}$ respectively. Then the cells were rinsed with cold DPBS buffer and irradiated with $365 \mathrm{~nm} \mathrm{UV} \mathrm{for} 15 \mathrm{~min}$ in cold DPBS buffer. The HeLa cells were harvested and pulldown was carried out using anti-HA magnetic beads as described above.

\section{General Information.}

Chemical reagents were purchased from Fisher, MilliporeSigma, Alfa and Acros. ${ }^{1} \mathrm{H}$ and ${ }^{13} \mathrm{C}$ NMR spectra were obtained with Bruker AV400 NMR Spectrometer with a CryoProbe. Chemical shifts are reported in $\delta(\mathrm{ppm})$ units and ${ }^{13} \mathrm{C}$ and ${ }^{1} \mathrm{H}$ signals from deuterated solvents were used as references. ACQUITY UPLC H-Class/SQD2 instrument equipped with an electrospray ionization (ESI) source was used to obtain mass spectra for small molecules. Xevo G2-S QTof instrument equipped with an electrospray ionization (ESI) source was used to obtain mass spectra for proteins. 60 GF254 (Merck) silica plate was used in thin layer chromatography (TLC) analysis. Small molecule column chromatography was conducted on silica gel (230-400 mesh). For the purification of ubiquitin probes, a Jupiter C18 column $(10 \times 250 \mathrm{~mm}$, 10 micron, Phenomenex, Torrance, CA) was used at flow rate of $4 \mathrm{~mL} / \mathrm{min}$. The UV absorbance at $214 \mathrm{~nm}$ was used to monitor the purification process. Water (with $0.1 \%$ formic acid) and acetonitrile (with $0.1 \%$ formic acid) were used as solvent $\mathrm{A}$ and $\mathrm{B}$ respectively.

GAPDH antibody was purchased from Santa Cruz Biotechnology Inc. (Dallas, TX). Anti-HA-tag and HRP-conjugated anti-mouse antibodies were purchased from MilliporeSigma (Bilerica, MA). HRPconjugated anti-rabbit antibody was purchased from Abcam (Cambridge, MA). Anti-HA magnetic beads and trypsin protease (MS grade) were purchased from ThermoFisher Scientific (Waltham, MA). 


\section{Experimental Procedures and Characterization Data}

Scheme S1. Synthesis of (2-(1-methyl-1H-pyrrol-2-yl)-2H-tetrazol-5-yl)methanamine (5)

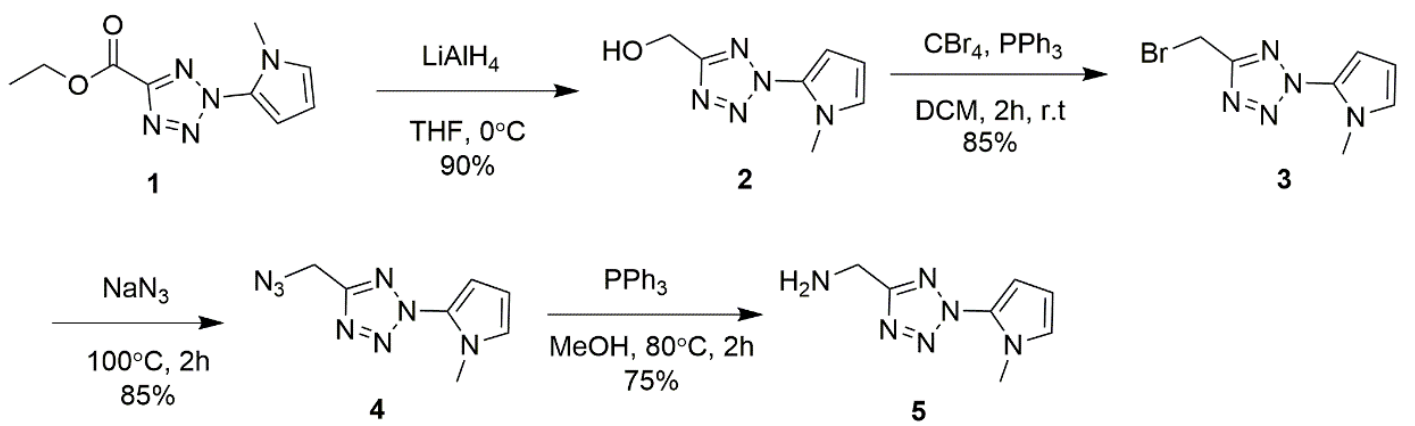

(2-(1-methyl-1H-pyrrol-2-yl)-2H-tetrazol-5-yl)methanol (2): Ethyl 2-(1-methyl-1H-pyrrol-2-yl)-2Htetrazole-5-carboxylate (1) was generated according to previous publication. ${ }^{[3]} \mathbf{1}$ (2.21 g, $\left.10 \mathrm{mmol}\right)$ was dissolved in $50 \mathrm{~mL}$ dried THF, then cooled to $0{ }^{\circ} \mathrm{C}$ with ice-bath. $\mathrm{LiAlH}_{4}(0.61 \mathrm{~g}, 16 \mathrm{mmol})$ was added in small portions during approximately 20 minutes. The mixture was stirred for another 20 minutes until the reaction was completed, as monitored by TLC. $1.5 \mathrm{~mL}$ water was added dropwise into the mixture to quench the reaction followed by filtration. The filtrate solution was dried with $\mathrm{Na}_{2} \mathrm{SO}_{4}$. The solvent was evaporated and the residue was purified by silica gel column chromatography with Hex:EtOAc (1:1) to provide (2-(1methyl-1H-pyrrol-2-yl)-2H-tetrazol-5-yl)methanol (1.61 g, $9 \mathrm{mmol}, 90 \%)$ as a colorless oil. ${ }^{1} \mathrm{H}$ NMR $(\mathrm{CDCl} 3,400 \mathrm{MHz}) \delta 6.70(\mathrm{t}, J=2.4 \mathrm{~Hz} 1 \mathrm{H}), 6.55(\mathrm{~m}, 1 \mathrm{H}), 6.22(\mathrm{~m}, 1 \mathrm{H}), 5.04(\mathrm{~s}, 2 \mathrm{H}), 3.68(\mathrm{~s}, 3 \mathrm{H}) ;{ }^{13} \mathrm{C}$ NMR (CDCl3, $100 \mathrm{MHz}): \delta$ 165.38, 123.22, 107.64, 105.73, 56.15, 34.75. MS (ESI, positive) $\mathrm{m} / \mathrm{z}$ calculated for $\mathrm{C}_{7} \mathrm{H}_{9} \mathrm{~N}_{5} \mathrm{O}[\mathrm{M}+\mathrm{H}]^{+}: 180.09$, found: 180.09 .

5-(bromomethyl)-2-(1-methyl-1H-pyrrol-2-yl)-2H-tetrazole (3): To a solution of (2-(1-methyl-1Hpyrrol-2-yl)-2H-tetrazol-5-yl)methanol (2) $(1.00 \mathrm{~g}, 5.59 \mathrm{mmol})$ and $\mathrm{PPh}_{3}(1.61 \mathrm{~g}, 6.15 \mathrm{mmol})$ in $50 \mathrm{~mL}$ $\mathrm{CH}_{2} \mathrm{Cl}_{2}, \mathrm{CBr}_{4}(2.78 \mathrm{~g}, 8.39 \mathrm{mmol})$ was added under stirring. Stirring was continued for $4 \mathrm{~h}$, then the solvent was evaporated and the crude residue was purified by silica gel column chromatography with Hex:EtOAc (3:1) to obtain 5-(bromomethyl)-2-(1-methyl-1H-pyrrol-2-yl)-2H-tetrazole (1.15 g, $4.75 \mathrm{mmol}, 85 \%)$ as a colorless oil. ${ }^{1} \mathrm{H}$ NMR (CDCl3, $\left.400 \mathrm{MHz}\right) \delta 6.71$ (t, $\left.J=2.4 \mathrm{~Hz} 1 \mathrm{H}\right), 6.57$ (m, 1H), $6.22(\mathrm{~m}, 1 \mathrm{H}), 4.70$ (s, 2H), 3.70 (s, 3H); $\left.{ }^{13} \mathrm{C} \mathrm{NMR} \mathrm{(CDCl3,} 100 \mathrm{MHz}\right): \delta 162.94,123.41,107.71,105.79,34.89$, 18.38. MS (ESI, positive) $\mathrm{m} / \mathrm{z}$ calculated for $\mathrm{C}_{7} \mathrm{H}_{9} \mathrm{~N}_{5} \mathrm{O}[\mathrm{M}+\mathrm{H}]^{+}: 242.00$, found: 242.02 .

5-(azidomethyl)-2-(1-methyl-1H-pyrrol-2-yl)-2H-tetrazole (4): 5-(bromomethyl)-2-(1-methyl-1Hpyrrol-2-yl)-2H-tetrazole (3) (1.00 g, $4.13 \mathrm{mmol})$ and sodium azide $(0.54 \mathrm{~g}, 8.26 \mathrm{mmol})$ were dissolved in $20 \mathrm{~mL}$ dry DMF and stirred at $100{ }^{\circ} \mathrm{C}$ for $2 \mathrm{~h}$. After cooling to room temperature, the suspension was diluted with water $(150 \mathrm{~mL})$. The aqueous layer was extracted with diethyl ether $(3 \times 30 \mathrm{~mL})$ and the combined organic layers were washed with water $(30 \mathrm{~mL})$ and brine $(2 \times 30 \mathrm{~mL})$, dried with anhydrous $\mathrm{Na}_{2} \mathrm{SO}_{4}$ and the solvent was evaporated and the crude residue was purified by silica gel column chromatography with 
Hex:EtOAc (3:1) to obtain 5-(azidomethyl)-2-(1-methyl-1H-pyrrol-2-yl)-2H-tetrazole (0.72 g, $3.51 \mathrm{mmol}$, $85 \%)$ as a colorless oil. ${ }^{1} \mathrm{H}$ NMR $(\mathrm{CDCl}, 400 \mathrm{MHz}) \delta 6.71(\mathrm{t}, J=2.4 \mathrm{~Hz} 1 \mathrm{H}), 6.58(\mathrm{~m}, 1 \mathrm{H}), 6.23(\mathrm{~m}, 1 \mathrm{H})$, 4.69 (s, 2H), 3.70 (s, 3H); ${ }^{13} \mathrm{C}$ NMR (CDCl3, $\left.100 \mathrm{MHz}\right): \delta 161.60,123.43,107.71,105.82,44.69,34.87$. MS (ESI, positive) m/z calculated for $\mathrm{C}_{7} \mathrm{H}_{7} \mathrm{~N}_{9}[\mathrm{M}+\mathrm{H}]^{+}: 205.10$, found: 205.08 .

(2-(1-methyl-1H-pyrrol-2-yl)-2H-tetrazol-5-yl)methanamine (5): To a solution of 5-(azidomethyl)-2(1-methyl-1H-pyrrol-2-yl)-2H-tetrazole (4) (0.50 g, $2.45 \mathrm{mmol})$ in $\mathrm{MeOH}(25 \mathrm{~mL})$ triphenylphosphine $(0.96 \mathrm{~g}, 3.68 \mathrm{mmol})$ was added. The resulting mixture was stirred at $80{ }^{\circ} \mathrm{C}$ for $1 \mathrm{~h}$. After evaporation of the solvent, the crude residue was purified by silica gel column chromatography with DCM:MeOH:Et $3 \mathrm{~N}$ (20:1:1) to obtain (2-(1-methyl-1H-pyrrol-2-yl)-2H-tetrazol-5-yl)methanamine (0.33 g, $1.84 \mathrm{mmol}, 75 \%)$ as a colorless oil. ${ }^{1} \mathrm{H} \mathrm{NMR}(\mathrm{CDCl} 3,400 \mathrm{MHz}) \delta 6.68(\mathrm{t}, J=2.4 \mathrm{~Hz} 1 \mathrm{H}), 6.51(\mathrm{~m}, 1 \mathrm{H}), 6.20(\mathrm{~m}, 1 \mathrm{H}), 4.22$ (s, 2H), 3.65 (s, 3H), 2.02 (s, 2H); $\left.{ }^{13} \mathrm{C} \mathrm{NMR} \mathrm{(CDCl3,} 100 \mathrm{MHz}\right): \delta 167.26,123.07,123.04,107.57,105.57$, 37.44, 34.66. MS (ESI, positive) m/z calculated for $\mathrm{C}_{7} \mathrm{H}_{7} \mathrm{~N}_{9}[\mathrm{M}+\mathrm{H}]^{+}: 179.10$, found: 179.17 . 
Scheme S2. Generation of HA-Cys $\left(\mathrm{cR}_{10}\right)-\mathrm{Ub}-\mathrm{TZ}$
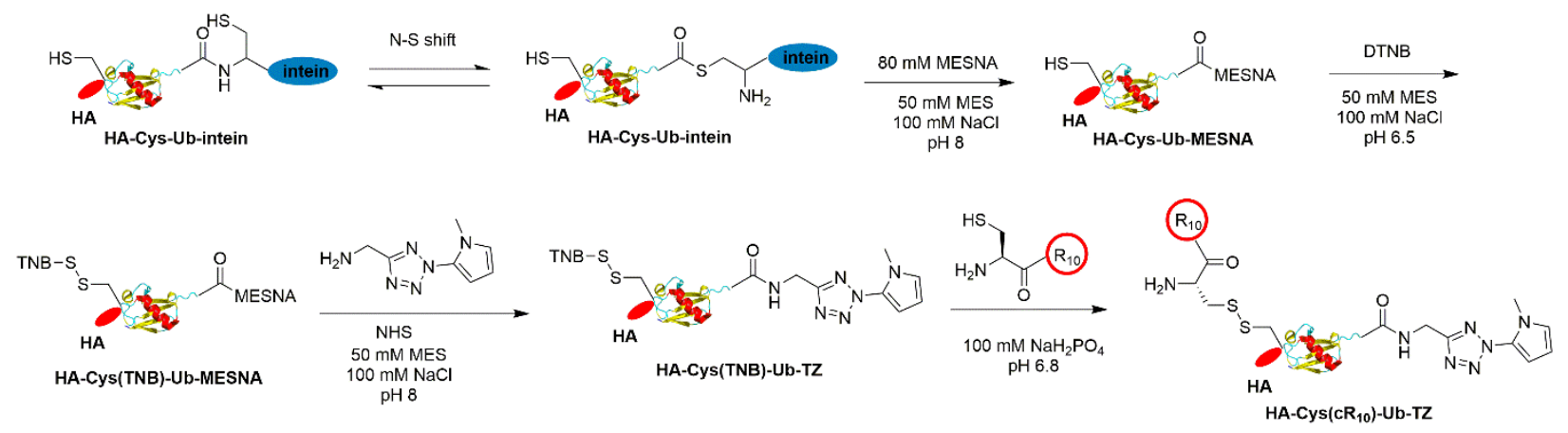

Generation of HA-Cys(TNB)-Ub-TZ. HA-Cys(TNB)-Ub-MESNA was generated as described in a previous publication. ${ }^{[1]}$ To a solution of HA-Cys(TNB)-Ub-MESNA (10 mg/mL, $\left.1 \mathrm{~mL}\right)$ in MES buffer (20 mM MES, $100 \mathrm{mM} \mathrm{NaCl}$, pH 6.5), NHS (500 $\mu \mathrm{L}, 2 \mathrm{M}$ solution in $\mathrm{ddH}_{2} \mathrm{O}, 1 \mathrm{mmol}, 1000$ eq.) and 5 (500 $\mu \mathrm{L}, 2 \mathrm{M}$ in DMSO solution, $1 \mathrm{mmol}, 1000$ eq.) were added sequentially. The final $\mathrm{pH}$ of the reaction solution was approximately 8 . The mixture was immediately vortexed and reacted at room temperature for $12 \mathrm{~h}$. The reaction mixture was then buffer exchanged into MES buffer (20 mM MES, $100 \mathrm{mM} \mathrm{NaCl}, \mathrm{pH}$ 6.5). The final concentration of the product was determined by Bradford assay. The molecular weight of HA-Cys(TNB)-Ub-TZ was determined by ESI-MS. (Expected mass: 10,052 Da, found mass: 10,052 Da, mass spectrum shown below).
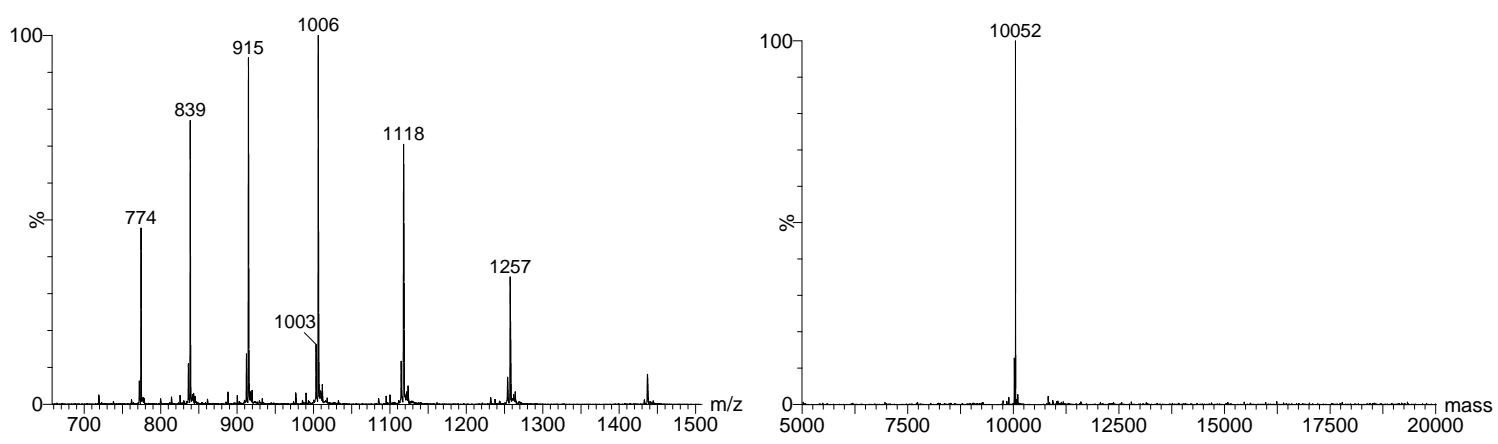

Generation of HA-Cys(cR $\mathbf{1 0})-\mathbf{U b}-\mathbf{T Z} . \mathrm{cR}_{10}$ peptide $(100 \mathrm{mg} / \mathrm{mL}, 0.14 \mathrm{~mL}, 6.4 \mu \mathrm{moL}, 20$ eq. $)$ was added to a $50 \mathrm{mM} \mathrm{NaH}{ }_{2} \mathrm{PO}_{4}$ buffer ( $\mathrm{pH}$ 6.8) solution containing HA-Cys(TNB)-Ub-TZ (1 mg/mL, $3.2 \mathrm{~mL}, 0.32$ $\mu \mathrm{mol})$. The mixture was vortexed and incubated at room temperature for $2 \mathrm{~h}$. The reaction mixture was then diluted with $1 \mathrm{~mL} 6 \mathrm{M}$ Guanidine- $\mathrm{HCl}$ and concentrated to a total volume of $1.0 \mathrm{~mL}$. A C18 HPLC column was used to purify the product. Solvent A is consisted of water with $0.1 \%$ formic acid, Solvent B is consisted of acetonitrile with $0.1 \%$ formic acid. Gradient in "time $\rightarrow \% \mathrm{~B}$ ": $0 \min \rightarrow 5 \%, 10 \min \rightarrow 30 \%, 70 \min \rightarrow$ $40 \%, 79 \mathrm{~min} \longrightarrow 95 \%$. The product was eluted out at approximately $28 \%$ buffer B. Fractions containing 
product were pooled and SpeedVac concentrated overnight. The pure product was dissolved in $6 \mathrm{M}$ Guanidine- $\mathrm{HCl}$ (pH 6.0), then buffer exchanged into MES buffer (20 mM MES, $100 \mathrm{mM} \mathrm{NaCl}, \mathrm{pH}$ 6.5) for four times. The molecular weight of HA-Cys $\left(\mathrm{cR}_{10}\right)-\mathrm{Ub}-\mathrm{TZ}$ was determined by ESI-MS. (Expected mass: 12,063 Da, found mass: 12,062 Da, mass spectrum shown below).
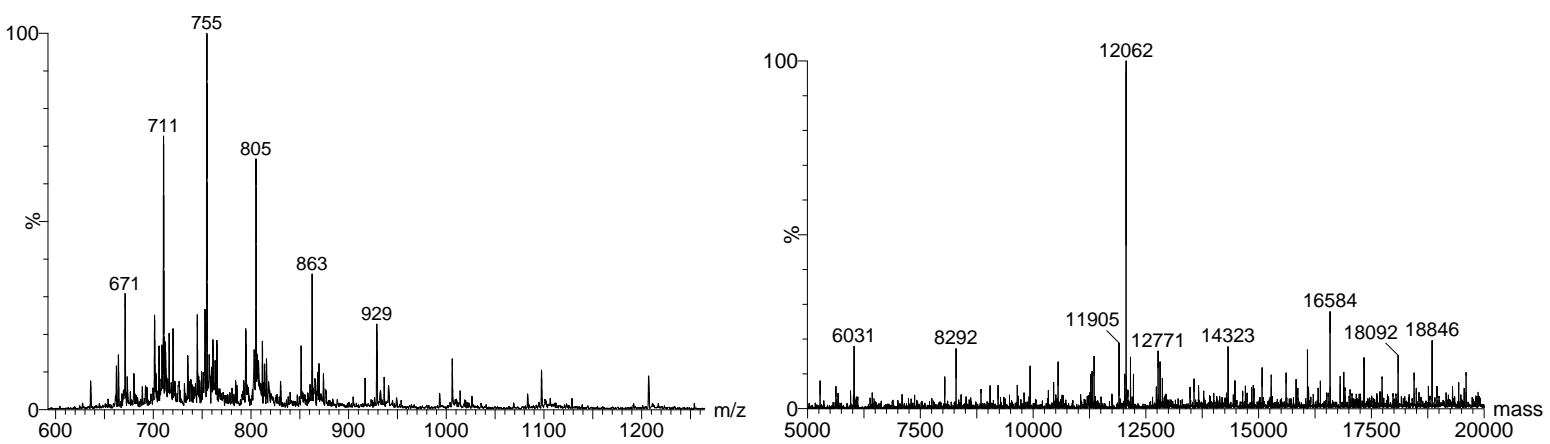

Generation of HA-Cys-Ub-TZ.

To a solution of HA-Cys(TNB)-Ub-TZ (500 $\mu \mathrm{L}, 1 \mathrm{mg} / \mathrm{mL})$ in MES buffer (20 mM MES, $100 \mathrm{mM} \mathrm{NaCl}$, $\mathrm{pH}$ 6.5), DTT (1 M, $0.1 \mathrm{~mL})$ was added. The mixture was immediately vortexed and incubated at room temperature for $1 \mathrm{~h}$. Following the reaction, the solution was buffer exchanged into MES buffer (20 mM MES, $100 \mathrm{mM} \mathrm{NaCl}, \mathrm{pH} \mathrm{6.5)} \mathrm{for} \mathrm{four} \mathrm{times.} \mathrm{The} \mathrm{final} \mathrm{concentration} \mathrm{of} \mathrm{the} \mathrm{product} \mathrm{was} \mathrm{determined} \mathrm{by}$ Bradford assay. The molecular weight of HA-Cys-Ub-TZ was determined by ESI-MS. (Expected mass: 9,855 Da, found mass: 9,855 Da, mass spectrum shown below).
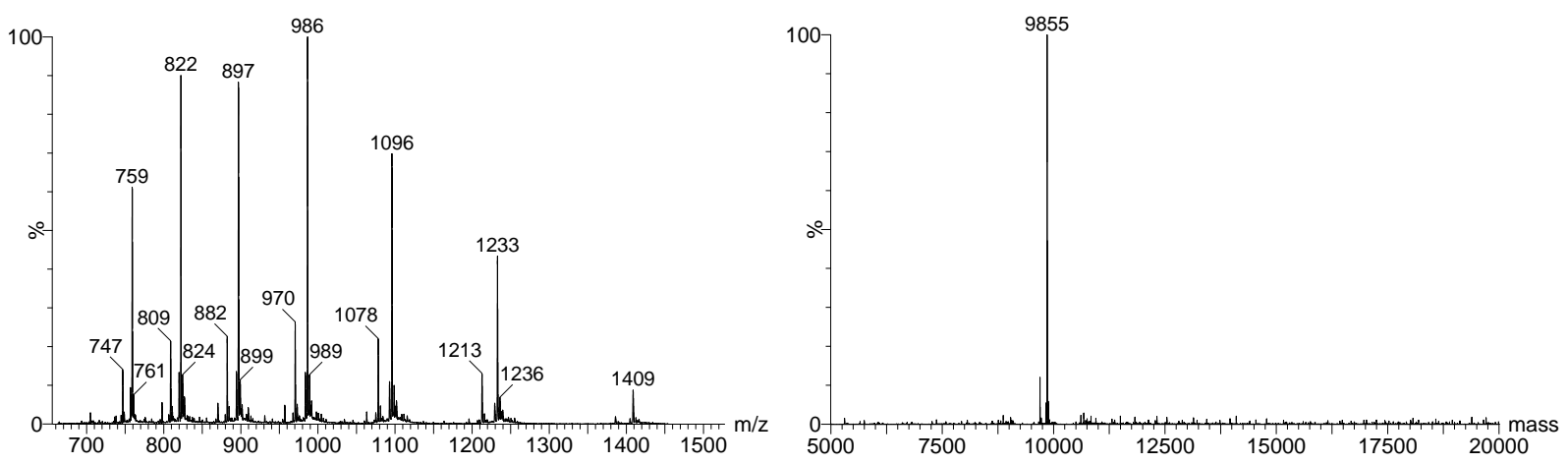


\section{Reference}

[1] W. Gui, C. A. Ott, K. Yang, J. S. Chung, S. Shen, Z. Zhuang, J Am Chem Soc 2018, 140, 1242412433.

[2] C. A. Ott, B. Baljinnyam, A. V. Zakharov, A. Jadhav, A. Simeonov, Z. Zhuang, ACS Chem Biol 2017, 12, 2399-2407.

[3] Y. Tian, M. P. Jacinto, Y. Zeng, Z. Yu, J. Qu, W. R. Liu, Q. Lin, J Am Chem Soc 2017, 139, 6078-6081. 
Jan17-2019-guiwj.1.1.1r

Wj2100

PROTON_16 CDCl3 /opt/topspin guiwj 57
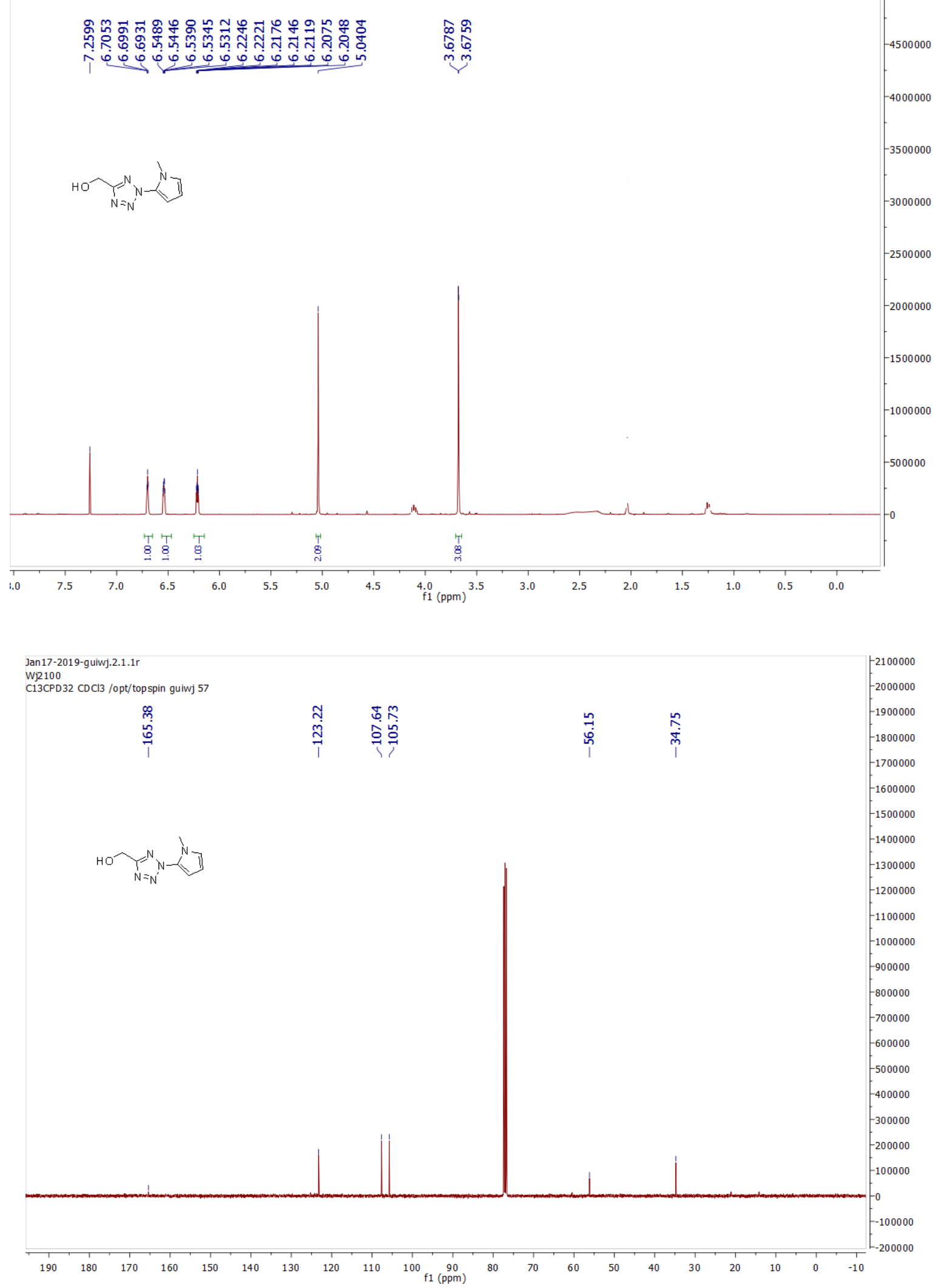
Jan30-2019-guiwj.1.1.1r

WJ2124

ROTON_16 CDCl3 /opt/topspin guiwj 5

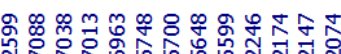

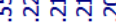

遇

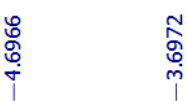

17000000

$-16000000$

$-15000000$

$-14000000$

$-13000000$

$-12000000$

$\operatorname{Cr}_{n=N}^{N} N^{n}$

$-11000000$

$-10000000$

$-9000000$

$-8000000$

$-7000000$

$-6000000$

5000000

$-4000000$

$-3000000$

2000000

$-1000000$

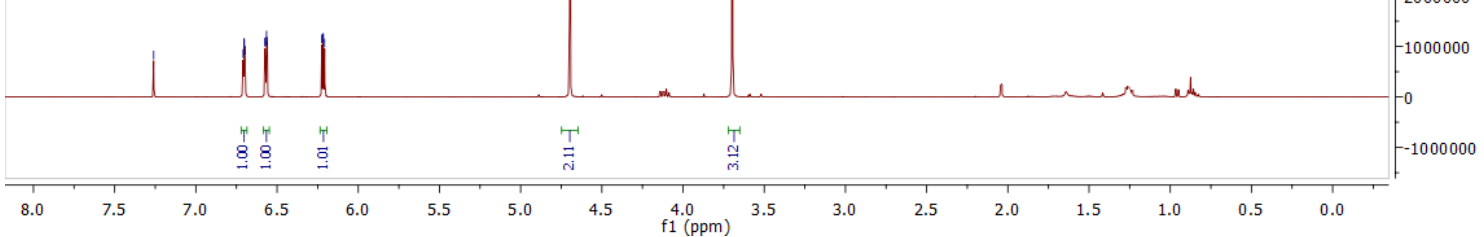

Jan30-2019-guiwj.2.1.1r WJ2124

C13CPD32 CDCl3/opt/topspin guiwj 5
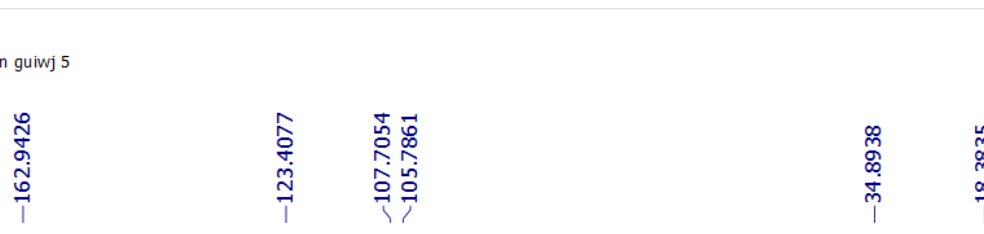

$-3200000$

3000000

$-2800000$

$-2600000$

$-2400000$

$-2200000$

$B={ }_{N=N}^{N}$

2000000

$-1800000$

$-1600000$

1400000

$-1200000$

1000000

800000

600000

$-400000$

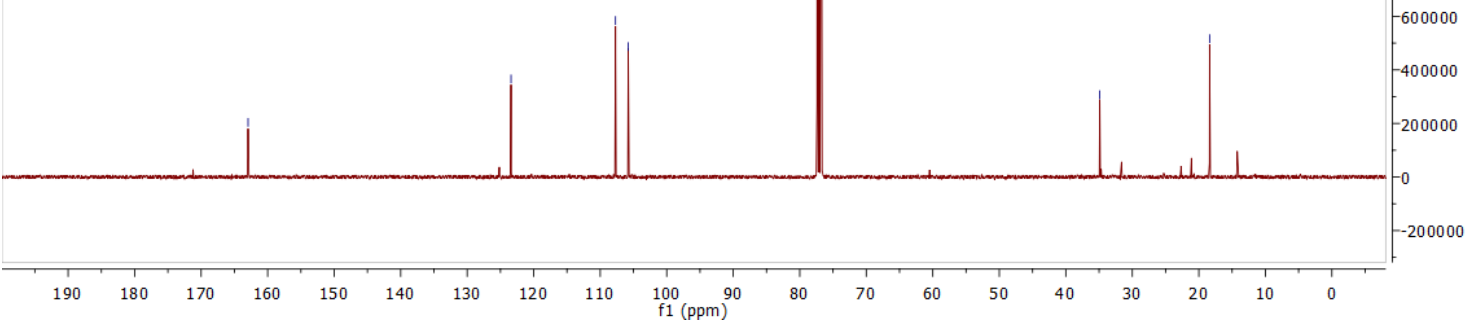




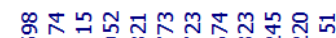

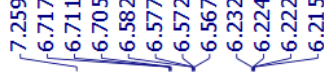

竞

$N_{n=N}^{N} N$

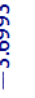

17000000

$-16000000$

$-15000000$

$-14000000$

$-13000000$

$-12000000$

$-11000000$

$-10000000$

9000000

$-8000000$

7000000

$-6000000$

$-5000000$

$-4000000$

$-3000000$

$-2000000$

$-1000000$

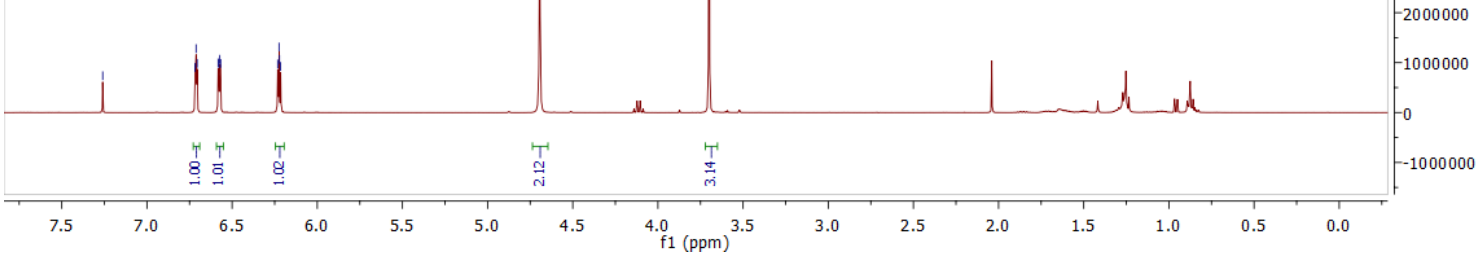

Jan30-2019-guiwj.4.1.1r

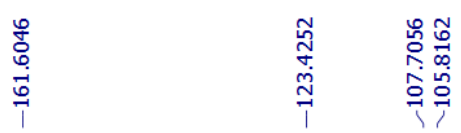

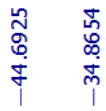

$-2800000$

ind

잉

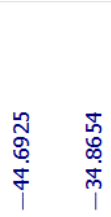

2600000

$-2400000$

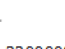

$-2200000$

$\mathrm{N}_{n=N^{n}}=N^{n}$

2000000

$-1800000$

$-1600000$

$-1400000$

$-1200000$

$-1000000$

$-800000$

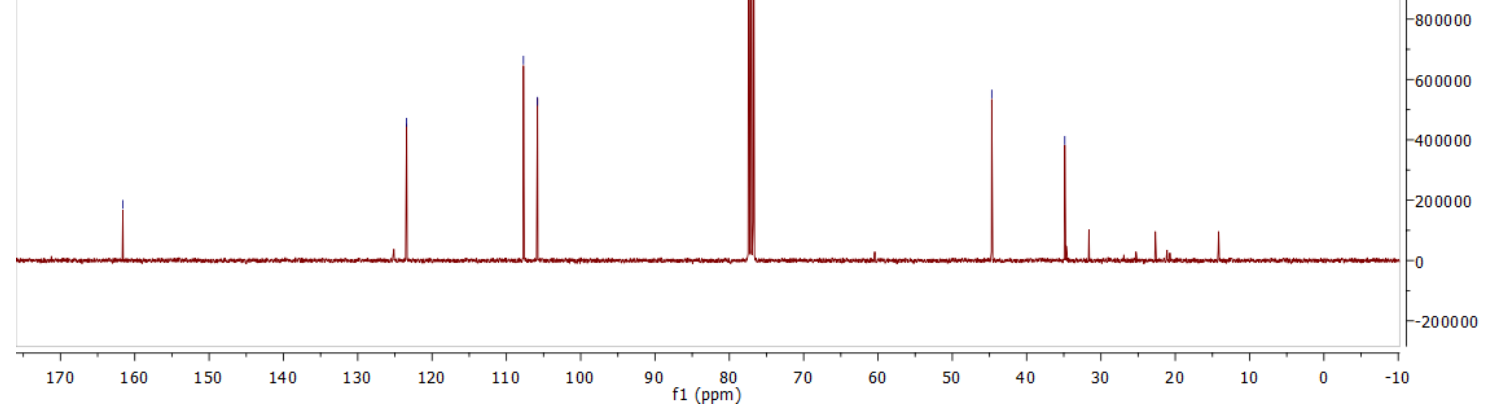


Oct23-2019-guiwj.1.1.1r

W]4001

PROTON_16 CDCl3 /opt/topspin guiwj 14

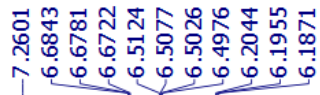

i ம

సั
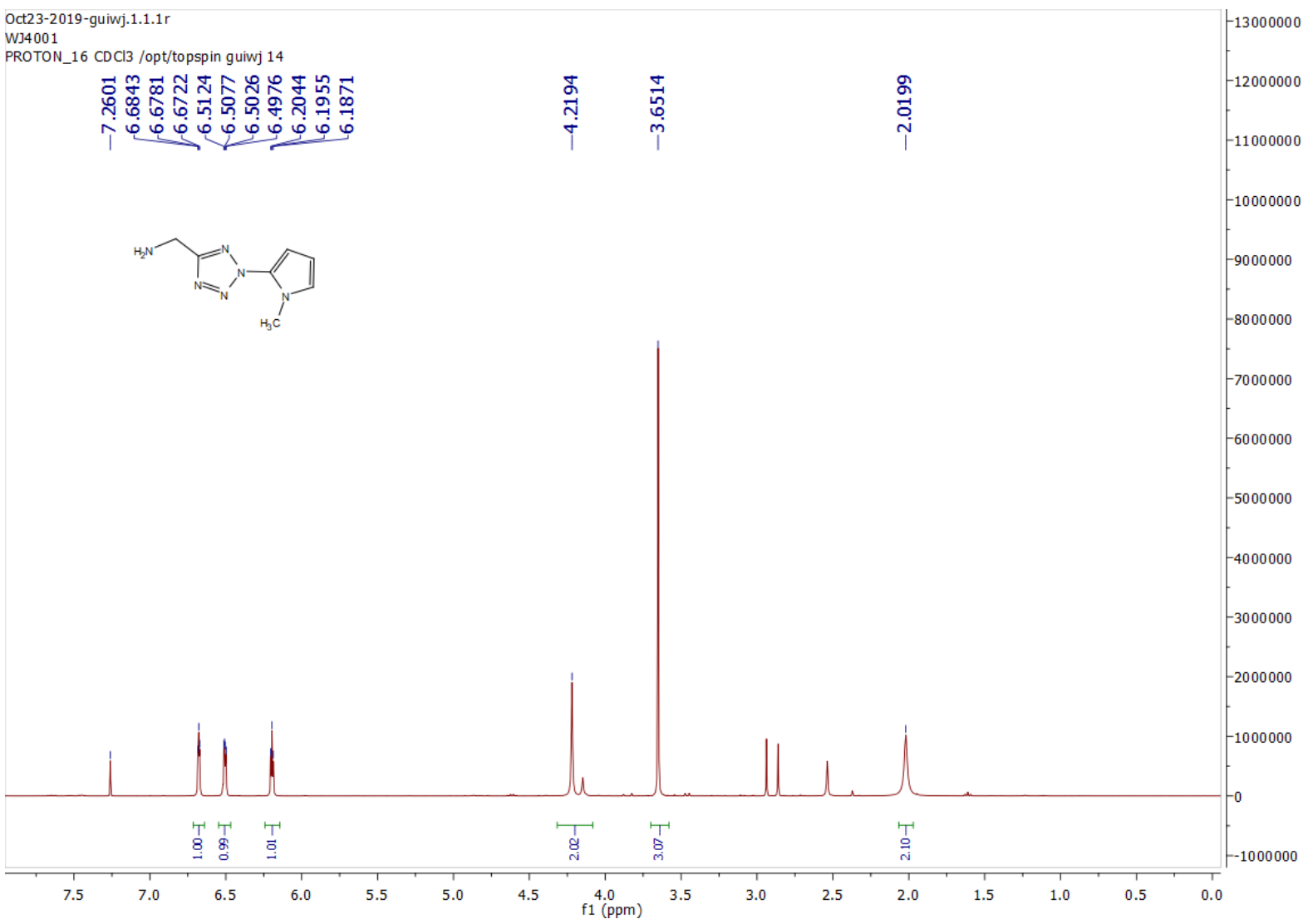

Oct23-2019-guiwj.2.1.1r

W]4001

C13CPD32 CDCl3 /opt/topspin guiwj 14

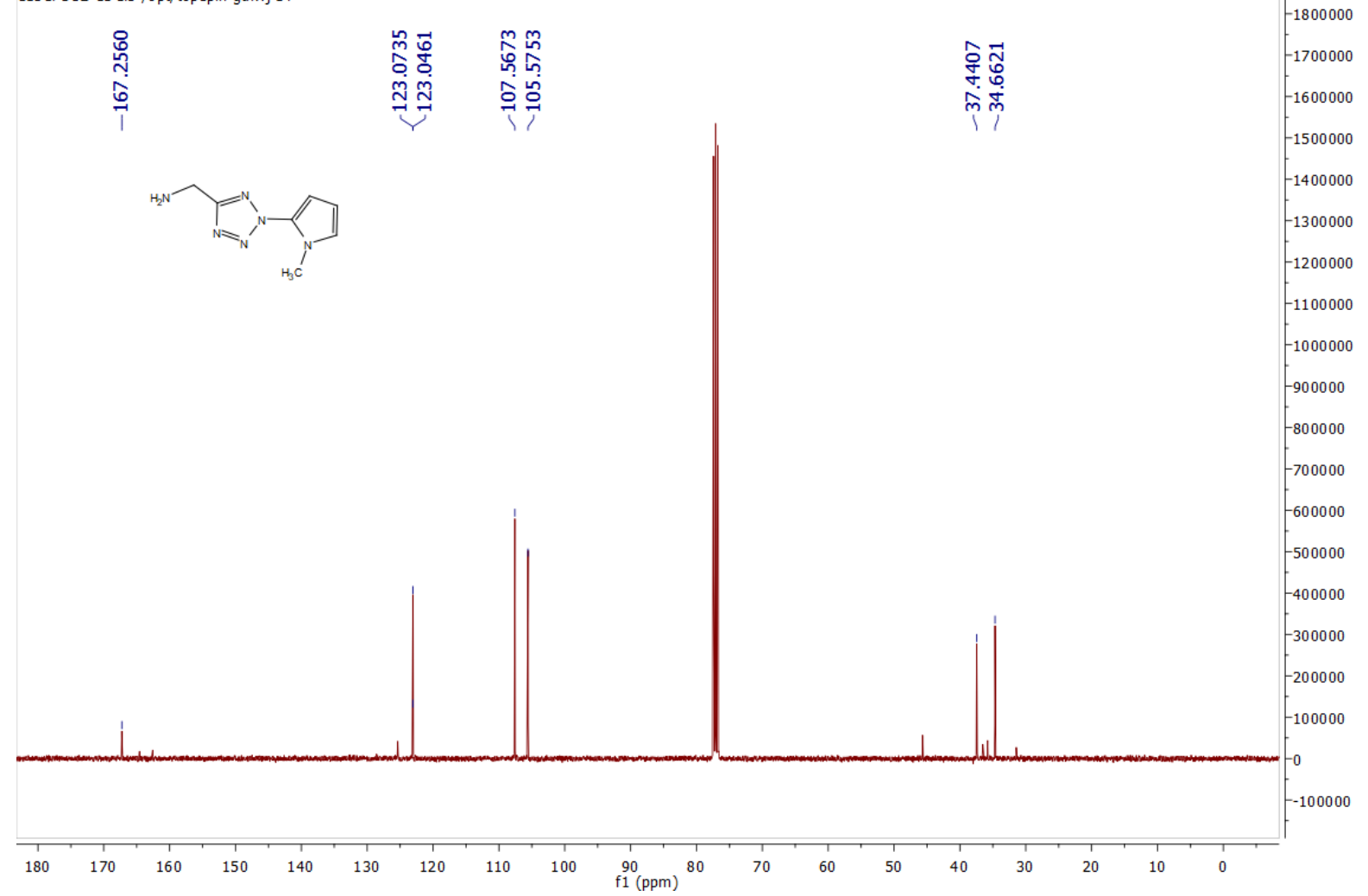

